\title{
Earthquake Monitoring in Southern California for Seventy-Seven Years (1932-2008)
}

\author{
by Kate Hutton, Jochen Woessner, and Egill Hauksson
}

\begin{abstract}
The Southern California Seismic Network (SCSN) has produced the SCSN earthquake catalog from 1932 to the present, a period of more than $77 \mathrm{yrs}$. This catalog consists of phase picks, hypocenters, and magnitudes. We present the history of the SCSN and the evolution of the catalog, to facilitate user understanding of its limitations and strengths. Hypocenters and magnitudes have improved in quality with time, as the number of stations has increased gradually from 7 to $\sim 400$ and the data acquisition and measuring procedures have become more sophisticated. The magnitude of completeness $\left(M_{\mathrm{c}}\right)$ of the network has improved from $M_{\mathrm{c}} \sim 3.25$ in the early years to $M_{\mathrm{c}} \sim 1.8$ at present, or better in the most densely instrumented areas. Mainshock-aftershock and swarm sequences and scattered individual background earthquakes characterize the seismicity of more than 470,000 events. The earthquake frequency-size distribution has an average $b$-value of $\sim 1.0$, with $M \geq 6.0$ events occurring approximately every 3 yrs. The three largest earthquakes recorded were $1952 M_{\mathrm{w}} 7.5$ Kern County, $1992 M_{\mathrm{w}} 7.3$ Landers, and $1999 M_{\mathrm{w}} 7.1$ Hector Mine sequences, and the three most damaging earthquakes were the $1933 M_{\mathrm{w}} 6.4$ Long Beach, $1971 M_{\mathrm{w}} 6.7$ San Fernando, and $1994 M_{\mathrm{w}} 6.7$ Northridge earthquakes. All of these events ruptured slow-slipping faults, located away from the main plate boundary fault, the San Andreas fault. Their aftershock sequences constitute about a third of the events in the catalog. The fast slipping southern San Andreas fault is relatively quiet at the microseismic level and has not had an $M>6$ earthquake since 1932. In contrast, the slower San Jacinto fault has the highest level of seismicity, including several $M>6$ events. Thus, the spatial and temporal seismicity patterns exhibit a complex relationship with the plate tectonic crustal deformation.
\end{abstract}

\section{Introduction}

In 1927, the Carnegie Institution of Washington began installing seismic stations to record and study local earthquakes in southern California. In particular, Wood (1916) had advocated research on the more frequent small earthquakes to improve understanding of the hazards from potentially damaging large earthquakes. By 1929, the seismic network consisted of seven stations (Table 1; Fig. 1). Much of the subsequent growth of the network in the years since was spurred on by the occurrence of the large $(M \geq 6.5)$ damaging earthquakes, including the $1952 M_{\mathrm{w}} 7.5$ Kern County, $1971 M_{\mathrm{w}}$ 6.7 San Fernando, $1992 M_{\mathrm{w}} 7.3$ Landers, $1994 M_{\mathrm{w}} 6.7$ Northridge, and the $1999 M_{\mathrm{w}}$ 7.1 Hector Mine earthquakes (Table 2).

The network was transferred to the California Institute of Technology (Caltech) in 1937 and integrated with the Seismological Laboratory. In the early 1970s, the Seismological Laboratory began collaborating with the U.S. Geological Survey (USGS) to operate what is now known as the Southern California Seismic Network (SCSN). At the end of 2008, the SCSN had grown to a total of 160 digital, broadband, and strong-motion stations, 30 digital accelerometers, 110 analog short-period stations, as well as data streams from $\sim 100$ shared stations from cooperating networks (Figs. 2 and 3). Thus the SCSN has evolved into the southern California facility that was suggested by Wood (1916).

The SCSN has produced a continuous regional earthquake catalog with more than 470,000 events. The need for representing the sizes of recorded earthquakes lead Richter and Gutenberg (Richter, 1935; Gutenberg and Richter, 1956; Richter, 1958) to formulate the first instrumental earthquake magnitude scale, now referred to as the local magnitude $M_{\mathrm{L}}$. Other magnitude scales for small earthquakes were later introduced and calibrated to match $M_{\mathrm{L}}$ on the average. For large earthquakes, the $M_{\mathrm{L}}$ scale saturates (Brune, 1970), and the $M_{\mathrm{w}}$ scale (Kanamori, 1977, 1978), now referred to as the moment magnitude (Hanks and Kanamori, 1979), is often used.

In recent years, the SCSN catalog, including hypocenter, magnitude, phase data, and digital waveforms where 
Table 1

List of Stations That Formed the Initial Seismic Network in Southern California: Early Caltech Seismic Network

\begin{tabular}{llcll}
\hline Code & \multicolumn{1}{c}{ Name } & On-Date (yyyy/mm/dd) & Off-Date (yyyy/mm/dd) & \multicolumn{1}{c}{ Comments } \\
\hline RVR & Riverside & $1926 / 10 / 19$ & In operation & \\
PAS & Pasadena & $1927 / 03 / 17$ & $2006 / 10 / 30$ & Replaced by PASC \\
LJC & La Jolla & $1927 / 05 / 04$ & $1952 / 07 / 30$ & Replaced by CPE \\
SBC & Santa Barbara & $1927 / 05 / 10$ & In operation & \\
MWC & Mount Wilson & $1928 / 04 / 23$ & In operation & \\
TIN & Tinemaha Reservoir & $1929 / 09 / 04$ & In operation & \\
HAI & Haiwee Reservoir & $1929 / 09 / 11$ & $1965 / 10 / 27$ & Replaced by CWC \\
\hline
\end{tabular}

available, have been transferred to the Southern California Earthquake Data Center (SCEDC) database (see the Data and Resources section) for distribution to users. The SCSN catalog has also been incorporated into a number of state- wide and national data sets to facilitate research and hazard estimation, including Toppazada et al. (1981), Kagan et al. (2006), Felzer and Cao (2008), and Wang et al. (2009), as well as the Advanced National Seismic System (ANSS;

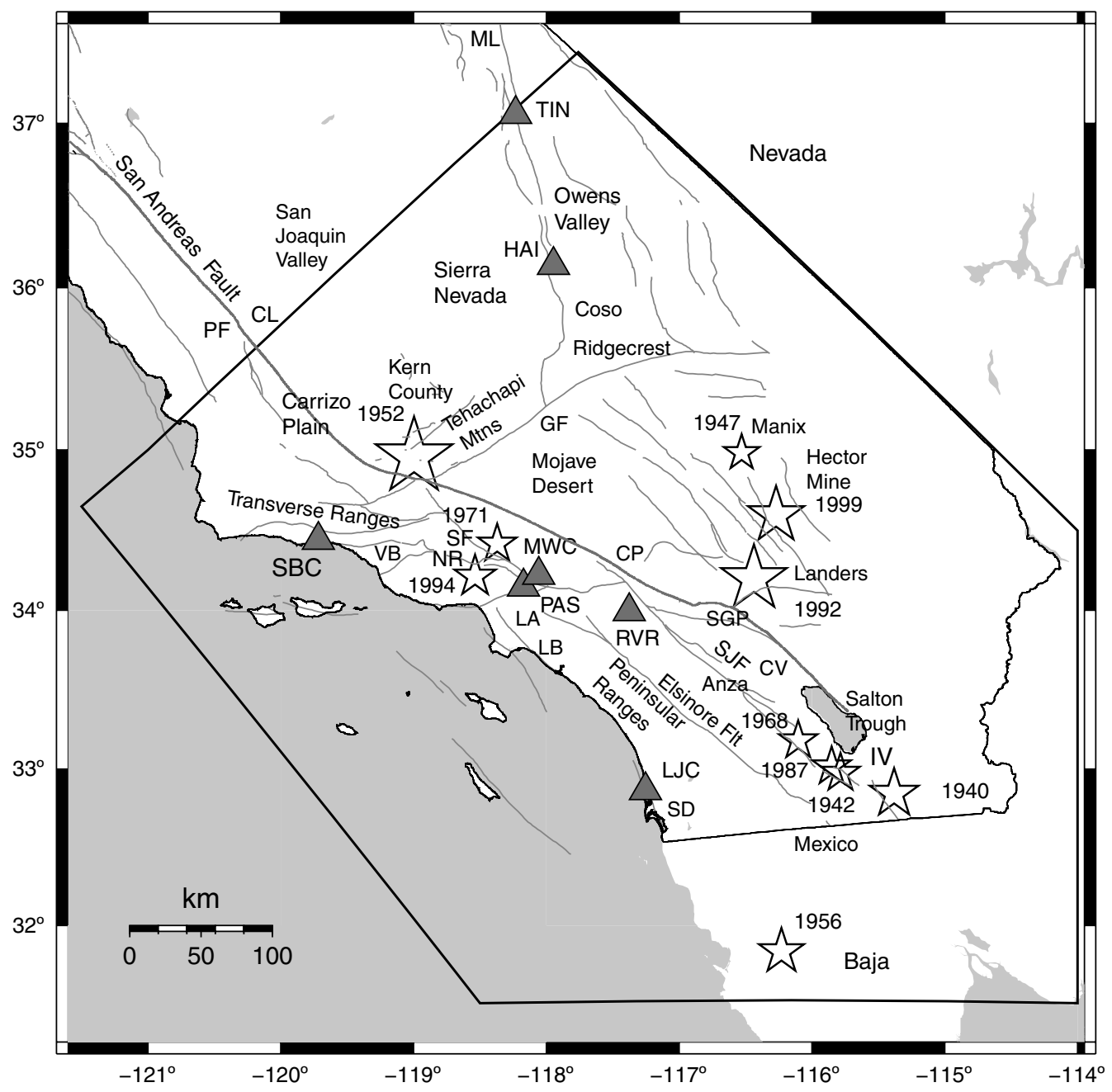

Figure 1. Map showing the location of the first seven stations of the SCSN stations (Table 1), the boundary of the SCSN coverage area (polygon), and the $M_{\mathrm{w}} 6.5$ and larger earthquakes from 1932 to 2008, within the region, shown as stars. 1940, Imperial Valley; 1942, Fish Creek Mountains; 1947, Manix; 1952, Kern County; 1956, San Miguel Baja California; 1968, Borrego Mountain; 1971, San Fernando; 1987, Superstition Hills; 1992, Landers; 1994, Northridge; 1999, Hector Mine; CL, Coalinga; GF, Garlock fault; CP, Cajon Pass; LA, Los Angeles; LB, Long Beach; ML, Mammoth Lakes; PF, Parkfield; SD, San Diego; SGP, San Gorgiono Pass; SJF, San Jacinto fault; VB, Ventura Basin. 
Table 2

Earthquakes of $M \geq 6.5$ Recorded by the SCSN

\begin{tabular}{cccccccccc}
\hline Date (yyyy mm dd) & Time & Latitude & Longitude & Depth $(\mathrm{km})$ & Magnitude & rms $(\mathrm{sec})$ & ERH $(\mathrm{km})$ & ERZ $(\mathrm{km})$ & ID Number \\
\hline 19400519 & 043640.50 & $32^{\circ} 50.65^{\prime}$ & $115^{\circ} 22.86^{\prime}$ & 06.0 & 6.90 & 0.42 & 12.8 & 31.6 & 3365279 \\
19421021 & 162211.98 & $32^{\circ} 58.52^{\prime}$ & $115^{\circ} 47.12^{\prime}$ & 06.0 & 6.60 & 0.34 & 04.0 & 31.6 & 3366099 \\
19470410 & 155805.11 & $34^{\circ} 58.97^{\prime}$ & $116^{\circ} 31.89^{\prime}$ & 06.0 & 6.50 & 0.51 & 04.5 & 31.6 & 3358945 \\
19520721 & 115214.54 & $34^{\circ} 57.49^{\prime}$ & $118^{\circ} 59.88^{\prime}$ & 06.0 & 7.50 & 0.39 & 01.4 & 31.6 & 3319401 \\
19560209 & 143241.91 & $31^{\circ} 49.93^{\prime}$ & $116^{\circ} 13.85^{\prime}$ & 06.0 & 6.80 & 0.10 & 04.3 & 31.6 & 3297521 \\
19560215 & 012035.27 & $31^{\circ} 08.94^{\prime}$ & $115^{\circ} 29.08^{\prime}$ & 06.0 & 6.52 & 0.67 & 13.8 & 31.6 & 3297567 \\
19680409 & 022858.39 & $33^{\circ} 10.79^{\prime}$ & $116^{\circ} 06.18^{\prime}$ & 10.0 & 6.60 & 0.33 & 00.9 & 31.6 & 3329122 \\
19710209 & 140041.92 & $34^{\circ} 24.96^{\prime}$ & $118^{\circ} 22.20^{\prime}$ & 09.0 & 6.60 & 0.25 & 01.1 & 02.4 & 3347678 \\
19871124 & 131556.71 & $33^{\circ} 00.90^{\prime}$ & $115^{\circ} 51.12^{\prime}$ & 11.2 & 6.60 & 0.39 & 00.3 & 00.9 & 628016 \\
19920628 & 115734.13 & $34^{\circ} 12.00^{\prime}$ & $116^{\circ} 26.22^{\prime}$ & 01.0 & 7.30 & 0.19 & 00.3 & 00.8 & 3031111 \\
19940117 & 123055.39 & $34^{\circ} 12.78^{\prime}$ & $118^{\circ} 32.22^{\prime}$ & 18.4 & 6.70 & 0.31 & 00.4 & 00.7 & 3144585 \\
19991016 & 094644.13 & $34^{\circ} 35.64^{\prime}$ & $116^{\circ} 16.26^{\prime}$ & 00.0 & 7.10 & 0.16 & 00.3 & 03.8 & 9108652 \\
\hline
\end{tabular}

rms, root mean square residual of observed minus calculated travel times; ERH, horizontal error; ERZ, vertical error. The focal depth is referred to the average station elevation.

see the Data and Resources section). In several special studies, the earthquakes in the SCSN catalog since 1981 have been relocated using 3D velocity models or waveform-based, double-difference methods (Hauksson, 2000; Hauksson and Shearer, 2005; Lin et al., 2007).

The SCSN has served in a role similar to other regional seismic networks in other parts of the United States and around the world. All of these networks have attempted to provide a complete earthquake catalog down to some minimum magnitude of completeness $\left(M_{\mathrm{c}}\right)$. The SCSN is unique because it has a continuous history of earthquake monitoring, with an average magnitude completeness achieving $M_{\mathrm{L}} \sim$ 3.25 since 1932 and $M_{\mathrm{L}} \sim 1.8$ since 1981. The instruments used from the inception of the network (Benioff and Wood-Anderson designs) were the first designed for high-sensitivity recording at short periods $(\sim 1 \mathrm{sec}$ period $)$, and the development of the $M_{\mathrm{L}}$ scale, originally based on the Wood-Anderson seismometers, contributed to long-term continuity and success of the SCSN catalog.

Allen et al. (1965), Friedman et al. (1976), Hileman et al. (1973), Hill et al. (1990), and Hutton et al. (1991) have all discussed the SCSN and the earthquake catalog. In this article, we summarize the network history and the methods used in earthquake catalog production. We also address the completeness of the catalog in various time periods, as a function of geographic location. Analyzing the catalog we are able to determine the long-term average spatial and temporal seismicity patterns. For purposes of this article, the "SCSN" and "SCSN earthquake catalog" refer to the entire time period since 1932.

\section{Southern California Seismic Network}

As the station density and geographical distribution evolved (Figs. 2 and 3), so did the technology, instrumentation, and data processing methods. In its present configuration, the SCSN is the most extensive and the data processing the most advanced it has ever been.

\section{Stations and Recording}

The first southern California seismographic stations were installed in the late 1920s. By 1932, instrumental reliability and station timing were considered good enough to begin cataloging local earthquakes in southern California (Richter, 1958; Hileman et al., 1973; Friedman et al., 1976). The early instrumentation consisted of, at minimum, one (in most cases, two) horizontal Wood-Anderson component (Wood and Anderson, 1925) and a higher-gain vertical Benioff variable reluctance short-period seismometer (Benioff, 1932). Recording was done by photographic drum recorders, with time marks by the station clock. Station clock drift was monitored via a photographic drum devoted to recording radio signals in the same commonly used shortwave frequency band at each station. It was up to the analyst to single out a recognizable random pattern and thus compare the station time marks with those recorded at the Pasadena station (PAS). Station clocks sometimes drifted many minutes per day. (Initially, we attempted to improve upon the time corrections by reconstructing this process and/or interpolating time corrections. We were mistaken in expecting to do better. The early analysts were very good at what they did.) A large procedural improvement occurred in 1963 with the introduction of WWVB time signals. All stations required a manual change of records every day, with telemetry via the U.S. Postal Service, so hypocentral determinations were delayed by days or weeks.

Station equipment remained mostly unchanged until the early 1970s. However, after 1960 some of the Benioff instruments were replaced with Ranger (Lehner, 1962) or Geotech S13 moving coil short-period $(1 \mathrm{~Hz})$ seismometers. Following the 1971 San Fernando earthquake, the Seismological Laboratory began cooperative operation of the SCSN with the USGS. Most of the new stations installed from that time until the 1980s were single-component short-period vertical stations with L4C seismometers and telemetry via leased telephone line or point-to-point radio link. With the early telemetered stations, recording was largely in the visible 

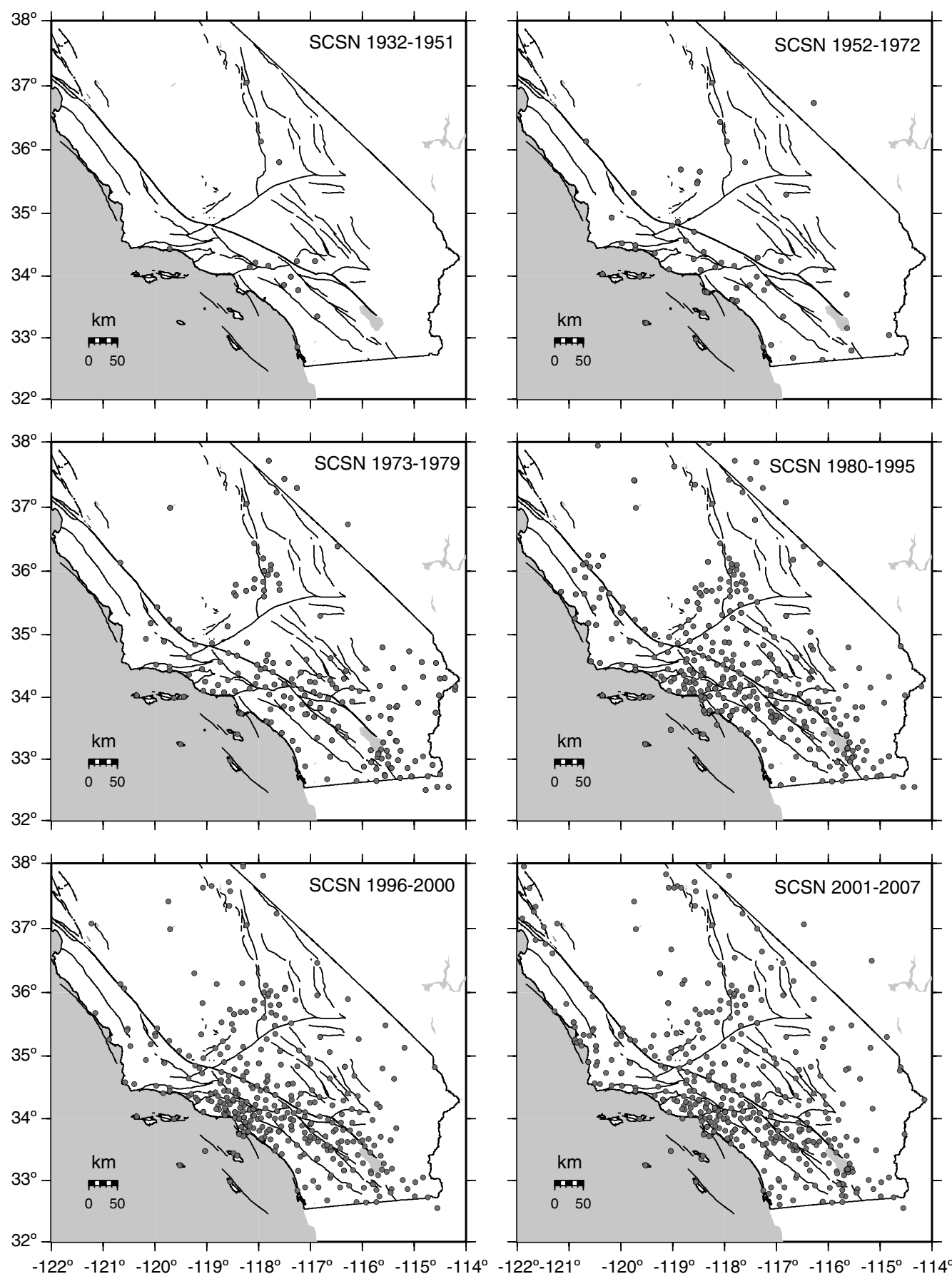

Figure 2. Maps of SCSN station distributions for six time periods as the station density and geographical coverage increased. The time periods were selected to show the network configuration when station density was fairly constant.

ink helicorder drum or Develocorder (microfilm) format. Time control continued to depend largely on WWVB or, during periods of garbled time code, on a local clock at the Seismological Laboratory. Telemetry allowed hypocentral locations and magnitudes to be determined in the near-realtime frame of a few minutes to a few days, depending on the urgency of the situation.

At the beginning of 1977, real-time computer recording of seismic network data began, with the Caltech/USGS Earth- quake Detection and Recording (CEDAR) system (see Table 3; Johnson, 1979). From 1977 through 1979, postprocessing was done via the first CEDAR version of interactive computer software. The more capable Caltech/USGS Seismic Processing (CUSP) system came into use in 1980 and was used through 2000. Beginning in 1988, preliminary automated locations were available within a few minutes after the earthquake, either from a hardware real-time processor unit (Allen, 1982) or later from the CUSP real-time system. Beginning in 


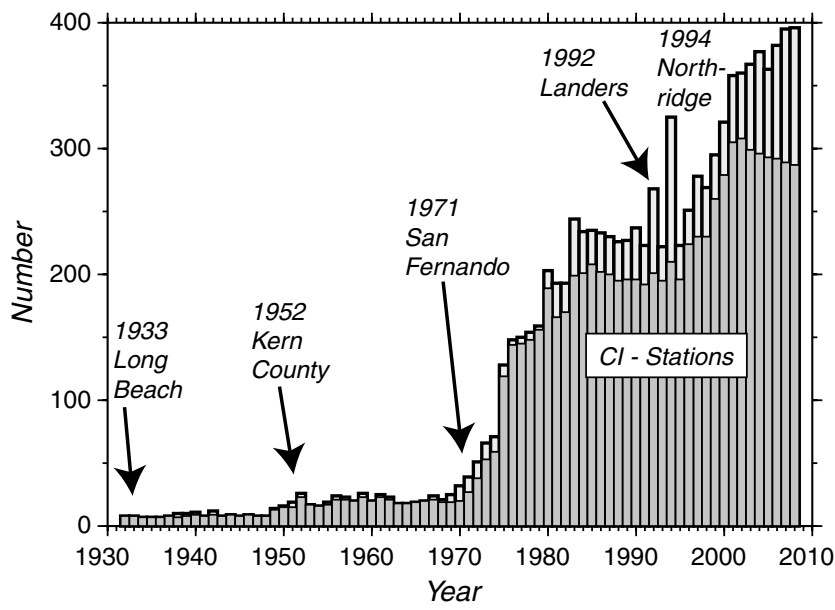

Figure 3. Histogram of operational seismic stations in the SCSN as a function of time. The SCSN operated (CI-stations) are shown with darker shading; those imported from other networks are shown with lighter shading. The increase in the number of stations follows major earthquakes as well as improvements in technology. Also, see Figure 2.

1991, if quality criteria were met, these preliminary data were released to emergency service organizations and the general public via the Caltech/USGS Broadcast of Earthquakes (CUBE) pager system (Kanamori et al., 1991) and later via Caltech and USGS Web sites. Automatic locations were and are reviewed by a seismic analyst in the workday time frame or on demand for publicly felt earthquakes. Time control came from WWVB (CEDAR and CUSP) and Inter-range instrumentation group (IRIG) or Geostationary Operational Environmental Satellites (GOES) time codes (CUSP). During this time period, much of the telemetry continued to be analog.

The first digital broadband and strong-motion station was installed at PAS in 1987 (Fig. 1). This station was the beginning of the TERRAscope project that included more than 24 new digital broadband and strong-motion stations (Kanamori et al., 1991). Nearly all of the new stations installed since have been of this type, including three components of broadband, high-dynamic-range digital (Streckheisen or Guralp) seismometers, along with three components of accelerometers (Kanamori et al., 1993; Hauksson et al., 2001). Each broadband station uses a Global Positioning System signal as its reference clock.

In the 1990s, with the CUSP processing system, broadband data coming in through digital telemetry had to be merged in postprocessing with the events detected by the real-time system using the analog-telemetered stations. The result is that only the larger events $\left(M_{\mathrm{L}} \approx 2.5\right.$ or larger) include broadband waveforms in their data sets. In January 2001, software developed under TriNet and now called ANSS Quake Monitoring System (AQMS) became the operational data acquisition system. The real-time detection includes both analog signals digitized in Pasadena (or at data-collection hubs in the field) and digital signals from the broadband and strong-motion stations.

\section{Data Processing}

Data processing procedures depended on the telemetry and recording methods. A summary of characteristics of the procedures used during six different time periods in the SCSN history is provided in Table 3. These time divisions are independent of those based on station density, used subsequently to analyze network sensitivity in the form of magnitude of completeness. We indicate the types of data acquisition used, the types of magnitudes most frequently calculated (see following), and some of the caveats that catalog users should be aware of.

Photographic and (pen and ink) helicorder drum recordings were the bread and butter of the network for its first 45 yrs. They were read by an analyst, for $P$ - and $S$-arrival time and peak amplitude, using a ruler and magnifier. The average reading error was $0.1 \mathrm{~mm}$ (or $0.1 \mathrm{sec}$ in time), and sometimes larger if the paper was not wrapped snugly enough around the drum. Locations were normally done graphically, with a compass on a map, although Nordquist (1962) later relocated most of larger events by computer. Amplitudes were normally read as half the full range of the largest single swing of the light beam or pen. Long-period energy from microseisms or teleseisms was ignored when reading small local earthquakes superposed on them. Starting in the early 1970s, the microfilm records from the develocorders were also read with a ruler, but the larger time format allowed for a reading error of about $0.02 \mathrm{sec}$. After the $P$ arrival, especially for the stations equipped with L4C seismometers, the traces were very underexposed, so that both $S$ arrivals and amplitudes were generally impossible to read. Coda duration was normally used for a magnitude estimate in these cases (Lee et al., 1972).

With the onset of digital recording, interactive analysis was done on a computer screen. The sampling rate has ranged from 62.5 samples/sec in 1977 to 100 samples/sec, with a few 80 samples/sec, data streams today. At first, the location software ran in batch mode, after the analyst had finished picking the arrivals. Without feedback to the analyst, multiple events and cross talk between the stations sometimes caused the assignment of inappropriate locations. Magnitudes were assigned (see the History of Local Magnitude $\left(M_{\mathrm{L}}\right)$ and History of Other Magnitudes sections) from coda decay rate (Johnson, 1979) or manual introduction of amplitudes from the stations that were equipped with Wood-Anderson seismometers. Beginning in the 1980s, synthetic WoodAnderson amplitudes (Kanamori et al., 1993) became available, from low-gain short-period channels and from the broadband stations.

Most events after 1977 originally had digital waveform files. Exceptions were those where the real-time system failed to detect the event, or the system was out of magnetic tape, or for some other reason was not operating. Because of 
Table 3

Overview of the SCSN Technology Improvements and Data Processing

\begin{tabular}{|c|c|c|}
\hline Time Period & SCSN Network Density, Data Recording, and Processing & SCSN Data Processing: Magnitude Types and Data Analysis Comments \\
\hline \multirow{5}{*}{$\begin{array}{l}\text { 1932-1951: early } \\
\text { network }\end{array}$} & Very sparse network of 7 stations & $M_{\mathrm{L}}$ or $M_{\mathrm{h}}$ from Wood-Anderson or Benioff seismometers \\
\hline & Data recorded on photographic drum records & Initial locations mostly based on $S-P$ times \\
\hline & $\begin{array}{l}\text { Data processing by hand by reading } \\
\text { photographic records }\end{array}$ & Some 2-station locations based on best guess \\
\hline & & Assumed locations (no phases) for some early aftershocks \\
\hline & & $\begin{array}{l}\text { In the late 1990s phases and amplitudes typed from phase cards. Events } \\
\text { were relocated and magnitudes redetermined. }\end{array}$ \\
\hline \multirow[t]{3}{*}{$\begin{array}{l}\text { 1952-1972: middle } \\
\text { network }\end{array}$} & $\begin{array}{l}\text { Sparse network with some added stations } \\
\text { following the } 1952 \text { earthquake }\end{array}$ & $M_{\mathrm{L}}$ or $M_{\mathrm{h}}$ from Wood-Anderson or Benioff seismometers \\
\hline & $\begin{array}{l}\text { Data recording on photographic and helicorder } \\
\text { visible drum records }\end{array}$ & $\begin{array}{l}\text { Data processing similar to earlier periods but computers } \\
\text { used for locations since early } 1960 \text { s }\end{array}$ \\
\hline & Data processing similar to $1932-1951$ & $\begin{array}{l}\text { In the late 1990s phases and amplitudes typed from phase } \\
\text { cards. Events were relocated and magnitudes redetermined. }\end{array}$ \\
\hline \multirow{2}{*}{$\begin{array}{l}\text { 1973-1976: } \\
\text { develocorder } \\
\text { network }\end{array}$} & $\begin{array}{l}\text { Increased station density due to } \\
\text { USGS/Caltech collaboration }\end{array}$ & $M_{\mathrm{L}}, M_{\mathrm{D}}$, or $M_{\mathrm{h}}$ magnitudes \\
\hline & $\begin{array}{l}\text { Data recording on develocorder microfilm } \\
\text { recording, and on photographic } \\
\text { and helicorder drums }\end{array}$ & Computer algorithms used for routine locations \\
\hline \multirow[t]{4}{*}{$\begin{array}{l}\text { 1977-March 1981: } \\
\text { CEDAR network }\end{array}$} & $\begin{array}{l}\text { Increased station density due to USGS/Caltech } \\
\text { collaboration }\end{array}$ & $M_{\mathrm{L}}, M_{\mathrm{ca}}$, or $M_{\mathrm{h}}$ magnitudes \\
\hline & $\begin{array}{l}\text { First online detection and recording, using } \\
\text { computers for digital processing }\end{array}$ & $\begin{array}{l}\text { Some event times may be wrong due to bad } \\
\text { WWVB time code }\end{array}$ \\
\hline & & Some waveforms missing due to bad magnetic tapes \\
\hline & & Missing events timed from prescan printouts or helicorders \\
\hline \multirow[t]{5}{*}{$\begin{array}{l}\text { April 1981-2001: } \\
\text { CUSP network }\end{array}$} & $\begin{array}{l}\text { In early 1990s TERRAscope and late 1990s } \\
\text { TriNet broadband stations added }\end{array}$ & $M_{\mathrm{L}}, M_{\mathrm{ca}}$, or $M_{\mathrm{h}}$ magnitudes, a few $M_{\mathrm{D}}$ values \\
\hline & $\begin{array}{l}\text { Second-generation real-time detection, } \\
\text { recording, and processing using CUSP }\end{array}$ & $\begin{array}{l}\text { Some event times may be wrong due to bad } \\
\text { WWVB time code }\end{array}$ \\
\hline & & May include some spuriously large $M_{\mathrm{ca}}$ values \\
\hline & & Similar processing to previous period; fewer problems \\
\hline & & Synthetic $M_{\mathrm{L}}$ off by up to 0.13 (see text for details) \\
\hline \multirow[t]{3}{*}{$\begin{array}{l}\text { 2001-present: Trinet/ } \\
\text { AQMS network }\end{array}$} & $\begin{array}{l}\text { Network size becomes stable with } \sim 300 \text { stations } \\
\text { in the CI network and } \sim 100 \text { imported stations } \\
\text { from partner networks }\end{array}$ & $M_{\mathrm{w}}, M_{\mathrm{L}}, M_{\mathrm{D}}$, or $M_{\mathrm{h}}$ magnitudes \\
\hline & $\begin{array}{l}\text { Third-generation real-time detection, recording, and } \\
\text { processing using AQMS software }\end{array}$ & Similar processing; even fewer problems \\
\hline & & $\begin{array}{l}\text { Landers and Northridge temporary digital stations } \\
\text { had incorrect clocks }\end{array}$ \\
\hline
\end{tabular}

deterioration of the magnetic media, however, an unfortunately large number of waveforms from 1977 through 1981 were not recoverable. In addition, none of the develocorder films were still readable, and the helicorder and photographic records are no longer accessible. Because currently available software allows interactive review by a seismic analyst, whereas the CEDAR software of the day did not, all of the computer phase data since the beginning of digital recording in 1977, for which digital waveforms still exist, were reviewed and/or repicked if necessary using an interactive software package (TIMIT or Jiggle), thus bringing the analysis as far as possible up to present standards. As a result of the variability in the quality of available data, the quality of the locations and magnitudes range widely, from those with digital waveforms and verifiable picks to those with only a few or inconsistent picks, unverifiable because of lack of waveforms.

All past data gaps or backlogs of unprocessed data have now been processed, entered into the permanent archive, and have been made available from the SCEDC. These backlogs resulted from time periods of rapidly evolving technology and software development and/or high seismicity. In addition, picks from the CUSP time period were incompletely loaded into the SCEDC database and required review and repicking in some cases. Time periods also existed for which many events lacked magnitudes from the initial processing.

\section{Earthquake Catalog}

The SCSN catalog consists of origin date and time, location, depth, magnitude, and some parameter uncertainties for 
over 470,000 events. To bring all the data since 1932 into the computer age, we have located all the events using modern methods and also recomputed all the $M_{\mathrm{L}} \mathrm{s}$ using the existing phase picks and amplitudes. Missing magnitudes have been added when possible from processing of available amplitude data and visual inspection of waveforms.

The SCSN reporting area has changed with time. The geographic reporting region of the SCSN extends from northern Baja, south of the United States-Mexico border, to the southeastern Carrizo Plain and Owens Valley in the north (Fig. 1). Since the 1930s Caltech also reported on the larger earthquakes in the Mammoth Lakes region using data from the nearby stations TIN and either HAI or CWC (Table 1). In our relocated catalog, we assigned the category of regional to these events. We did not take as much care with the locations or magnitudes of regional events as we did with the local events inside our current coverage area, because even in the best cases the event locations were poorly determined. When the USGS dense coverage in the Mammoth Lakes region began in the 1970s, Caltech stopped reporting for the region. A similar situation applied to the Parkfield and Coalinga areas. Although Caltech reported the largest events before the 1980s, these events are also now listed as regional in our catalog. Additional data for both of these regions can be found in the Northern California Seismic Network (NCSN) catalog. Earthquakes as far south as $31^{\circ} \mathrm{N}$ are included as local, provided they are detected and located by the SCSN. However, the locations are progressively of poorer quality the farther south the epicenters are.

There are six event categories available to us for labeling events in the archive. These are local (le), quarry blast (qb, which we applied to all chemical explosions, including highway construction blasts and geophysical shots), regional (re), sonic (sn; various sonic booms, including National Aeronautics and Space Administration [NASA] space shuttle approaches to the landing site at Edwards Air Force Base), nuclear (nt; Nevada Test Site shots, for which we used the officially announced locations but computed our own $M_{\mathrm{L}}$ ), and teleseism (te). The user of the catalog will find a few unknown (uk) events also remaining, which we left on a caseby-case basis, with an explanation assigned to the "Remark" field in the database. For the analyses in this article, we only included local events. Table 4 shows the numbers of events of each of these types, during time periods defined by the technology and data processing methods. Many unknown (uk) events listed for the CUSP time period (1980-2000) are the raw copies of the analog-telemetry files for which another copy has the digital telemetry data merged into it. (The short versions were created because of the length of time it took to demultiplex the incoming telemetry files for large events. The long versions were saved in cases where the digital data were merged into a shortened version of the raw file, that is, the primary local event has digital data, but a shorter time window, while the unknown copy of the same event has the full time window, so that the long versions remain available to the user and not lost.) Any time problems, which for the analogtelemetry stations affected all stations equally, and hence preserved the hypocentral location, were cleaned up before analog and digital data were merged together.

Anything unusual encountered in the relocations is also indicated in the "Remark" field. In some cases, the earthquake locations were fine, but the time code was unreadable, leading to a small or large uncertainly in the time of the event, noted in the "Remark" field.

To provide a consistent comparison with events in the older parts of the catalog, we have not incorporated the double-difference locations from Hauksson and Shearer (2005). However, these are archived and available from the SCEDC as alternate catalogs.

\section{Hypocenter Relocations}

In most cases, we used HYPOINVERSE for the relocations (Klein, 2002). For events processed or reprocessed under CUSP between 1983 and 2000, a similar software module (Johnson, 1979) was used. In the very early years of the network, in particular during the 1933 Long Beach earthquake sequence (1933 $\left.M_{\mathrm{w}} 6.4\right)$, only $S-P$ times were available (Hauksson and Gross, 1991). Because HYPOINVERSE does not handle $S-P$ times, we used the 3D hypocentral location program SIMULPS (Thurber, 1993). In addition, many locations for the early aftershocks in the Long Beach sequence were taken directly from Hauksson and Gross (1991).

Table 4

Number and Types of Events Recorded by SCSN: Cataloged Events of Different Types

\begin{tabular}{|c|c|c|c|c|c|c|c|c|c|c|c|}
\hline \multirow[b]{3}{*}{ Period } & \multirow[b]{3}{*}{ Years } & \multicolumn{10}{|c|}{ Number of Earthquakes } \\
\hline & & \multicolumn{2}{|c|}{ Local } & \multicolumn{2}{|c|}{ Quarry } & \multicolumn{2}{|c|}{ Regional } & \multicolumn{2}{|c|}{ Nuclear } & \multicolumn{2}{|c|}{ Unknown } \\
\hline & & le & le/yr & $\mathrm{qb}$ & $\mathrm{qb} / \mathrm{yr}$ & re & re/yr & nt & $\mathrm{nt} / \mathrm{yr}$ & uk & uk/yr \\
\hline 1932-1951 & 20 & 8325 & 416 & 172 & 8.6 & 496 & 24.8 & 11 & 0.6 & 561 & 28.1 \\
\hline 1952-1972 & 21 & 8425 & 401 & 367 & 17.5 & 559 & 26.6 & 388 & 18.5 & 16 & 0.8 \\
\hline 1973-1979 & 7 & 26,732 & 3820 & 4283 & 611.9 & 1413 & 201.8 & 117 & 16.7 & 370 & 52.9 \\
\hline 1980-1995 & 16 & 262,054 & 16,378 & 19,772 & 1235.8 & 19,151 & 1196.9 & 174 & 10.9 & 1072 & 67 \\
\hline 1996-2000 & 5 & 84,576 & 16,915 & 6753 & 1350.6 & 3610 & 722 & - & - & 4696 & 939.2 \\
\hline 2001-2008 & 8 & 98,043 & 12,255 & 5526 & 690.8 & 3848 & 481.0 & - & - & 48 & 6.0 \\
\hline
\end{tabular}

le, local; qb, quarry; re, regional; nt, nuclear; uk, unknown. 
All of the events (except the Long Beach earthquake sequence) were located using the Hadley-Kanamori (HK) model 1D velocity model (Table 5) (Kanamori and Hadley, 1975; Hadley and Kanamori, 1977). This model is appropriate for the Mojave Desert region and the Transverse ranges but provides a poor approximation in the deep basins such as the Imperial Valley, Los Angeles basin, and Ventura basin, where the sedimentary layers delay the $P$ waves by up to $1.0 \mathrm{sec}$ and inappropriately deepen the hypocentral solutions. In regions, such as the Imperial Valley, where computed hypocenters were unusually deep for the known geology, we simply imposed a depth limit of $15 \mathrm{~km}$. Any events whose hypocenters were calculated deeper than that were relocated with the depth held fixed at $15 \mathrm{~km}$. However, there are some regions in southern California with legitimate hypocenters at depths greater than $15 \mathrm{~km}$ (the Peninsular ranges, San Gorgonio pass, etc.), even as deep as $35 \mathrm{~km}$ in some cases (e.g. Ventura basin; Bryant and Jones, 1992). These deep hypocenters remain in the catalog. For events with no arrivals close enough to constrain a depth (approximately 30-40 km epicentral distance, depending on the depth), the depth was generally held fixed at $6 \mathrm{~km}$, as has been data processing practice since the late 1970s. This practice applied unless some other information was known (such as quarry blasts occurring at $0 \mathrm{~km}$ depth). In the future, we plan to use a 3D velocity model for routine SCSN locations (Hauksson, 2000).

\section{Location Accuracies}

Pick time accuracy has improved with the technology. Accuracy is estimated to have been $0.1-0.2 \mathrm{sec}$ for photographic or helicorder drum recordings. A somewhat larger contribution came from time control problems during the pretelemetry time period when each station had its own clock. This clock error did not affect the $S-P$ time used in the graphical locations but does contribute uncertainty to later computer relocations. Once telemetry started, all stations except the few very remote stations that were still recorded onsite were on the same clock, so that clock error did not affect the earthquake locations. $P$ times picked from the develocorder microfilm systems were generally readable to the nearest $0.02 \mathrm{sec}$ relative to WWVB traces at the top and bottom of each film. For the stations equipped with $1 \mathrm{~Hz}$ seismometers (L4C Mark Products), most $S$ times were not readable because the $P$-wave coda saturated the telemetry and underexposed the

Table 5

The 1D Velocity Model Used by the SCSN (Hadley and Kanamori, 1977)

\begin{tabular}{cc}
\hline \multicolumn{2}{c}{ HK Model with $V_{P} / V_{S}$ Ratio of 1.73} \\
\hline Depth to Top of Layer $(\mathrm{km})$ & $P$-Velocity $(\mathrm{km} / \mathrm{sec})$ \\
\hline 0.0 & 5.5 \\
5.5 & 6.3 \\
16.0 & 6.7 \\
32.0 & 7.8 \\
\hline
\end{tabular}

film trace. Sites equipped with the Ranger seismometers were somewhat better at recording legible $S$ arrivals than those with L4C seismometers. With digitally recorded data, the reading error for impulsive arrivals can be as good as the sampling rate. In 1977, this rate was 62.5 samples/ sec (0.016 sec accuracy). Digitization rates have increased quickly to 80 samples $/ \mathrm{sec}(0.0125 \mathrm{sec})$ and 100 samples $/ \mathrm{sec}(0.01 \mathrm{sec})$, and beyond, since that time.

Once the network progressed to digital recording and analysis, errors due to the velocity model probably rivaled those due to the reading error. The nominal error bars calculated by using HYPOINVERSE for most of the $M \geq 3.0$ events located within the network from 1932 to 1973 are less than $6 \mathrm{~km}$. Following 1973, with the denser network, most nominal error bars are less than $3 \mathrm{~km}$. However, both CEDAR software and HYPOINVERSE use a system of pick weight codes, starting with the highest quality picks being assigned 0 (full weight), followed by 1 (3/4 weight), 2 (half weight), 3 (1/4 weight), and 4 (no weight) for the lowest quality picks, based on the analyst's estimated pick time accuracy (Klein, 2002). Although the pick weights were originally defined by time uncertainty for develocorder readings, their use in practice has been rather subjective. The 0 weight is usually given to those picks that can be localized to within one sample at whatever the digitization rate may be. Those that can be localized to 2 or 3 samples generally get a 1 weight, etc. The 4 weights are used as markers on the record, with no credibility. One side effect of historical development of technology is that the time definition of a given weight has drifted with time, which may confuse some users and may also affect the location error estimates. In general, comparison of the catalog locations with the $3 \mathrm{D}$ relocations, which used cross-correlation methods (Hauksson, 2000; Lin et al., 2007), show that the SCSN catalog errors estimated by HYPOINVERSE are reasonable.

\section{History of Local Magnitude $\left(M_{\mathrm{L}}\right)$}

In the early years, most of the magnitudes assigned to southern California earthquakes have been $M_{\mathrm{L}}$ (Richter, 1935). Initially, these magnitudes were based on amplitudes read from the photographically recorded Wood-Anderson seismometers. However, these instruments were significantly limited in dynamic range $\left(M_{\mathrm{L}}\right.$ could be determined only in the range from $\sim 2.5$ to $\sim 6.3$ within the geographic extent of the network); they were incompatible with modern digital telemetry and data analysis. All photographic WoodAnderson seismometers were removed from operation in August 1992. The current $M_{\mathrm{L}}$ practice generates synthetic Wood-Anderson records from the horizontal components of the broadband and accelerometer stations (Kanamori et al., 1993). For a time period in the 1980s, amplitudes were also obtained from synthetic records using data from low-gain short-period stations (Wald et al., 1990).

In Richter's original formulation (Richter, 1935, 1958), local magnitude was defined as the logarithm of the peak 
amplitude of the waveform on a Wood-Anderson seismometer located $100 \mathrm{~km}$ away from the epicenter. The zero point was chosen such that an earthquake with a $1.0 \mathrm{~mm}$ amplitude on the Wood-Anderson instrument, at this standard $(100 \mathrm{~km})$ distance, had a magnitude of 3.0,

$$
M_{\mathrm{L}}=\log _{10} A-\log A_{0}+C_{s},
$$

where $A$ is the amplitude in millimeters, $-\log A_{0}$ is an empirically determined attenuation function (of epicentral distance), which Richter provided in tabular form, and $C_{s}$ is an empirically determined station correction for each instrument. On the photographic records, the amplitude that was actually read was half the peak-to-peak distance on the largest single swing of the trace, which could range from $0.1 \mathrm{~mm}$ to between 70 and $100 \mathrm{~mm}$, depending on the photographic exposure of the trace. For most records $(\geq 95 \%)$, the peak occurred on the $S$ wave.

Richter's original attenuation table was derived from a small data set. SCSN analysts who analyzed the older data were well aware that this formulation yielded magnitudes that were too small for epicentral distances of less than about $50 \mathrm{~km}$ and too large for distances greater than about $250 \mathrm{~km}$. Hutton and Boore (1987) and Kanamori et al. (1993) recomputed attenuation as an analytic function, based on thousands of amplitudes. To determine $M_{\mathrm{L}}$ values, we used the Kanamori et al. form of the attenuation function, with revised constants and station corrections (Y. Polet, personal comm., 2000):

$$
\begin{aligned}
M_{\mathrm{L}} & =\log _{10} A+\log _{10} A_{0}+C_{s}, \\
A_{0} & =1.14 \log _{10}(r)+0.002193 r+0.4985 .
\end{aligned}
$$

$A$ is the amplitude and $r$ is the hypocentral (slant) distance. $C_{s}$ is an empirical station correction for each component (channel) to account for instrumental and geologic factors not otherwise included. Amplitudes are used out to an empirically determined distance cutoff of

$$
D=170.0 M_{\mathrm{L}}-205.0
$$

or $30 \mathrm{~km}$, whichever is larger, determined using a preliminary $M_{\mathrm{L}}$ estimate using only waveforms from the closest stations. Amplitudes must not approach the clipping level of the instrument and must have a signal-to-noise ratio of at least 8 . The earthquake's $M_{\mathrm{L}}$ is the median of all qualifying channel $M_{\mathrm{L}}$ estimates. Outliers are eliminated using Chauvenet's criterion (e.g., Taylor, 1997) with an outlier threshold of 0.5 (H. Kanamori, personal comm., 2008). Amplitudes are rejected if they lie in the tails of the normal distribution.

The computation of $M_{\mathrm{L}}$ s using amplitudes from synthetic records assumes an instrument gain. In contrast, for the old data with actual Wood-Anderson readings, the exact gain of the instrument is not important, because the WoodAnderson instrument defines the $M_{\mathrm{L}}$ scale. Wood and Anderson (1925) gave the nominal static magnification of their instrument as 2800. Uhrhammer and Collins (1990), however, argue for a true gain value of 2080. An error of that size would cause an magnitude step of 0.13 in the catalog magnitudes, thus affecting the seismicity rate as a function of time as digital stations were installed. For statewide uniformity, the SCSN decided to adapt the gain of 2080 for the SCSN WoodAnderson instruments, although the gains may have been different depending on the instrument manufacturer.

A new statewide consistent $M_{\mathrm{L}}$ station calibration with a complete set of corrections and a corresponding attenuation function is now available (Hellweg et al., 2007). Since January 2008, we have used this new algorithm and corrections for the SCSN $M_{\mathrm{L}}$ s and we plan to redetermine the magnitudes back to 2001. We are able to compute $M_{\mathrm{L}}$ for most earthquakes as small as 1.0 and below. The most obvious difference between this new calibration and the previous one affects the smallest earthquakes $\left(M_{\mathrm{L}}<2.0\right)$. This change results from two factors: (1) the details of a more complex attenuation function and (2) using a high-pass filter to remove long-period noise before evaluating automatically amplitudes of very small earthquakes riding on large long-period motion, such as microseisms. The $M_{\mathrm{L}}$ s computed using the statewide calibration, in the 3.25 and greater range, are on average approximately 0.07 units smaller than the previously computed ones because a compromise had to be made to reach statewide calibration. This compromise consisted of selecting a certain set of reference components to have historical station correction values (Hellweg et al., 2007).

\section{History of Other Magnitudes}

Because the $M_{\mathrm{L}}$ scale saturates above approximately magnitude 6.3, the moment magnitude $M_{\mathrm{w}}$ (Brune, 1970; Clinton et al., 2006) has been used for larger events. The formula for deriving $M_{\mathrm{w}}$ from seismic moment that minimizes rounding errors and that we use is (Lay and Wallace, 1995)

$$
M_{\mathrm{w}}=\log _{10}\left(M_{0}\right) / 1.5-10.73 \text {. }
$$

For smaller earthquakes, coda-amplitude magnitude $M_{\text {ca }}$ (Johnson, 1979), duration magnitude $M_{\mathrm{D}}$ (Lee et al., 1972), and various manually determined stopgap magnitude methods all labeled hand magnitude $M_{\mathrm{h}}$ have been used for earthquakes for which $M_{\mathrm{L}}$ determination was not possible.

During 1972-1976, earthquakes were detected and picked through the scanning and measuring of develocorder (microfilm) recordings. Magnitudes $\left(M_{\mathrm{D}}\right)$ were determined from the total duration of the seismic signal (Lee et al., 1972). $M_{\mathrm{D}}$ has since been adapted for automatic processing under the Earthworm system (Johnson et al., 1995). Under CEDAR and CUSP, which covered the time period from 1977 to 2000 , most magnitudes $\left(M_{\mathrm{ca}}\right)$ were computed by fitting an exponential function to the coda decay on the (digitized) ana$\log$ stations (Johnson, 1979). $M_{\mathrm{ca}}$ s were obtainable for earthquakes smaller than about 4.0, provided estimates were available for a sufficient number of stations and no noise 
or other earthquakes interfered with the coda recording. In the case of multiple events, the results were unpredictable, with some spurious large magnitudes resulting. These spurious magnitudes could be detected by comparing, for example, the $M_{\mathrm{ca}}$ with the number of picks or the presence or absence of Wood-Anderson readings. $M_{\text {ca }}$ was calibrated using events with $\operatorname{good} M_{\mathrm{L}}$, which at that time used the tabular $-\log A_{0}$ function. Comparison of $M_{\mathrm{ca}}$ and $M_{\mathrm{L}}$ for the same events yielded an approximately linear relationship with a scatter of about \pm 0.3 in the difference. Well-constrained $M_{\mathrm{ca}}$ s correspond fairly well to $M_{\mathrm{L}}$ in the range from about 1.0 to 3.5 but tend to be overestimates in the upper part of this range. To correct for an apparent calibration error that occurred in 1981 we regressed the two magnitude types linearly and correct the $M_{\mathrm{ca}} \mathrm{s}$. This change had the effect of lowering the $M_{\mathrm{ca}} \mathrm{s}$ in 1981 by 0.4 magnitude units on average.

Because of the relatively low magnification of the WoodAnderson instrument, the higher-gain vertical-component Benioff instruments detected a significant number of earthquakes that were too small to read on the Wood-Anderson instruments. To handle these small earthquakes before the advent of digital recording, station corrections were empirically determined for the short-period verticals, assuming that the usual $-\log A_{0}$ attenuation function applied. This allowed determination of practical, if not definitive, magnitudes $\left(M_{\mathrm{h}}\right)$ for smaller events. In extreme situations all of the usual magnitude determinations may have failed. This was caused by different situations, such as too small earthquake size, noise, or multiple entwined seismograms. In these cases magnitudes may have been determined using amplitude ratios with other events at the same location, duration of the seismic signal, or, rarely, other methods of less accuracy (considered preferable to listing no magnitude at all). The lower quality estimates from all of these methods are listed in the catalog under the magnitude type $M_{\mathrm{h}}$, where the h may refer to helicorder, hand, or human determined magnitude.

The moment magnitude $M_{\mathrm{w}}$ determined in near-real time (Dreger and Helmberger, 1990; Clinton et al., 2006) is currently used if either $M_{\mathrm{w}}$ or $M_{\mathrm{L}}$ is 5.0 or larger. $M_{\mathrm{w}}$ is generally considered to be a better magnitude, if available, because of its physics-based definition, and because it uses the long-period waveform and takes into account directional properties of the seismic radiation. For prebroadband earthquakes of 6.0 or larger, we assigned $M_{\mathrm{w}}$ values from the literature (Hutton and Jones, 1993).

In many cases, multiple magnitudes are listed in the database for each earthquake. One of these magnitudes is specified as the preferred magnitude for the event. We strive to designate the best magnitude available for each individual earthquake. $M_{\mathrm{w}}$ is preferred for $M 5.0+$ earthquakes if it meets quality criteria (variance reduction greater than $60 \%$ ). For earthquakes smaller then 5.0, we prefer $M_{\mathrm{L}}$ if it passes quality criteria (greater than 5 calibrated channels contributing, sometimes fewer among the old events) due to our long history with this magnitude type and the large number of data available from the broadband network. We have analyzed the relationship between $M_{\mathrm{w}}$ and $M_{\mathrm{L}}$ (Fig. 4). There is a nonlinear relationship between the two magnitude types, although this relationship is somewhat geographically dependent. The two magnitudes match fairly well at approximately 6.0, but

(a)

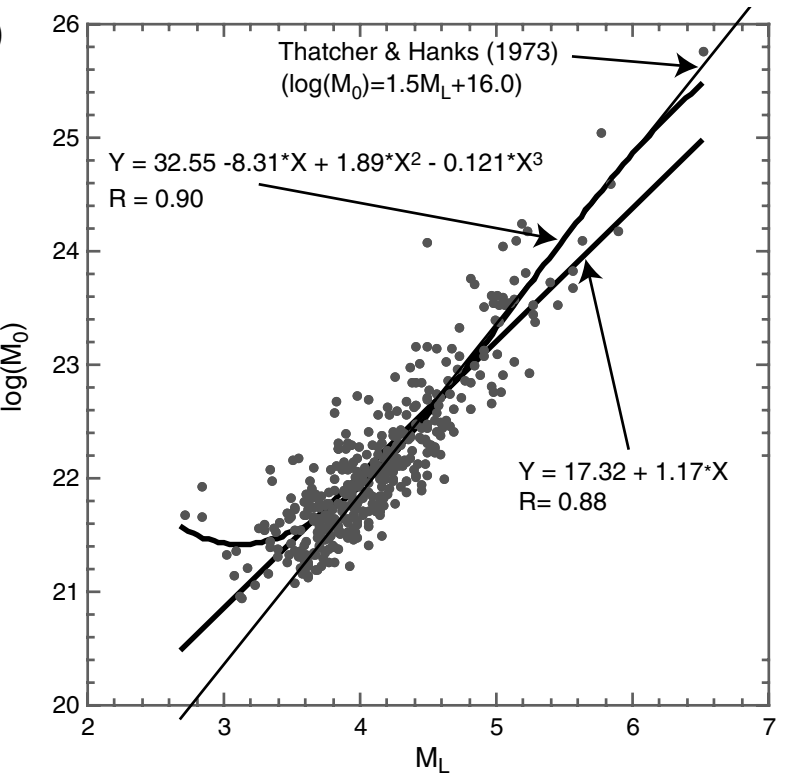

(b)

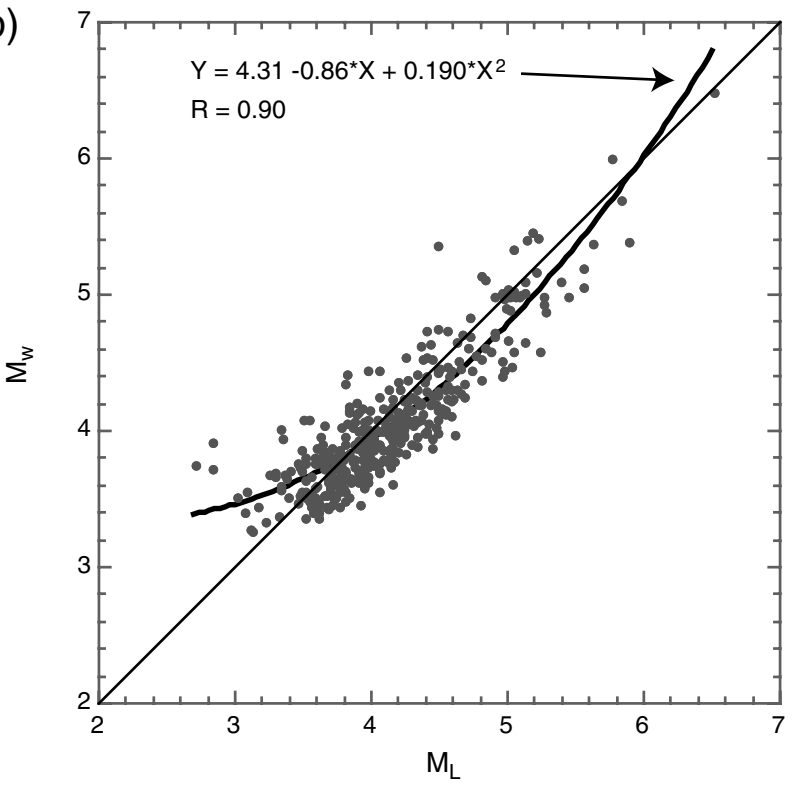

Figure 4. (a) Regression of the logarithm of the seismic moment $\left(M_{0}\right)$ and $M_{\mathrm{L}}$ for earthquakes recorded by the SCSN since 1999. Also included for comparison is the $\log \left(M_{0}\right)$ versus $M_{\mathrm{L}}$ relation from Thatcher and Hanks (1973) as the thin line. The thick, straight line is a regression fit to our data, including regression formula. The thick, curved line is the quadratic fit to the data, with regression formula. (b) Regression of the $M_{\mathrm{w}}$ and $M_{\mathrm{L}}$ for the events that had variance reduction greater than $60 \%$. A thin line with a slope of 1.0 is shown for comparison. The quadratic fit shows effects of noise levels on $M_{\mathrm{w}}$ at low magnitudes and saturation of the $M_{\mathrm{L}}$ at large magnitudes because Wood-Anderson instrumentation response does not adequately describe the size of large earthquakes. 
in the 4.0-5.0 range, $M_{\mathrm{w}}$ is often smaller than $M_{\mathrm{L}}$ by several tenths of a magnitude unit.

For earthquakes that fail quality criteria for all of the other types, we currently use $M_{\mathrm{h}}$ as the preferred magnitude. Some interactive estimation, such as event duration for $M_{\mathrm{h}}$ or selection of amplitudes for $M_{\mathrm{L}}$, is still required in cases where multiple earthquakes, weather, or cultural noise complicate the records. With the old data, such estimates could be fairly arbitrary. For example, in the develocorder days of the 1970 s, most earthquakes smaller than about 2.0 were designated 1.7. Because the develocorder films were unreadable, we were unable to improve upon this rough estimate. As in the other time periods, earthquakes that were large enough to appear on Wood-Anderson recordings were assigned the usual $M_{\mathrm{L}}$ magnitudes.

\section{Magnitude Completeness}

We estimated the magnitude of completeness $\left(M_{\mathrm{c}}\right)$ of the SCSN catalog, accounting for the entire magnitude range (EMR), including the range of magnitudes reported incompletely (Woessner and Wiemer, 2005). The approach is similar to that of Ogata and Katsura (1993) and uses a maximumlikelihood estimator to model the two parts of the frequencymagnitude distribution (FMD).

We estimated $M_{\mathrm{c}}$ assuming that, for a given volume, a simple power law approximates the FMD above the completeness level. The FMD describes the relationship between the frequency of occurrence and the magnitude of earthquakes (Ishimoto and Iida, 1939; Gutenberg and Richter, 1944):

$$
\log _{10} N(M)=a-b M \quad M \geq M_{\mathrm{c}},
$$

where $N(M)$ refers to the frequency of earthquakes with magnitudes larger than or equal to $M$. The $b$-value describes the relative size distribution of events, and the $a$-value describes the seismicity of the space-time volume.

To determine the $M_{\mathrm{c}}$ of a data set, we computed a model of the FMD for each assumed $M_{\mathrm{c}}$ obtaining a log-likelihood value, ascending from small to large magnitudes. For an assumed $M_{\mathrm{c}}$ we computed $a$ - and $b$-values using a maximumlikelihood estimate (Aki, 1965; Utsu, 1965). For data below the assumed $M_{\mathrm{c}}$, a normal cumulative distribution function $q(M \mid \mu, \sigma)$ that describes the detection capability as a function of magnitude was fitted to the data. $q(M \mid \mu, \sigma)$ denotes the probability of a seismic network to detect an earthquake of a certain magnitude and can be written as

$$
\begin{aligned}
& q(M \mid \mu, \sigma)=\frac{1}{\sigma \sqrt{2 \pi}} \int_{-\infty}^{M_{c}} \exp -\frac{(M-\mu)^{2}}{2 \sigma^{2}} d M \\
& \text { for } M<M_{\mathrm{c}}, \\
& q(M \mid \mu, \sigma)=1 \text { for } M \geq M_{\mathrm{c}},
\end{aligned}
$$

where $\mu$ is the magnitude at which $50 \%$ of the earthquakes are detected and $\sigma$ denotes the standard deviation describing the width of the range where earthquakes are partially detected.
Higher values of $\sigma$ indicate that the detection capability of a specific network decreases more rapidly for smaller magnitude earthquakes. Earthquakes with magnitudes equal to or greater than $M_{\mathrm{c}}$ are assumed to be detected with a probability of one. The free parameters $\mu$ and $\sigma$ are estimated using a maximum-likelihood estimator. The best-fitting model is the one that maximizes the log-likelihood function for four parameters: $\mu$ and $\sigma$, as well as $a$ and $b$.

We computed maps of the $M_{\mathrm{c}}$ for six time periods, in which the station density, data acquisition, and the magnitude determination procedures were mainly consistent in time or changed only slightly (Table 3 ). The completeness estimates were computed using a grid space of $0.05^{\circ} \times 0.05^{\circ}$ using hypocenters that were located at depth $d \leq 30 \mathrm{~km}$. We used two different sampling approaches, both applying the EMR method to determine $M_{\mathrm{c}}$. In the first approach, we sampled earthquakes in vertical cylinders with radii of $r=20 \mathrm{~km}$, requiring a minimum of $N=100$ earthquakes to determine completeness estimates for either part of the FMD model (Fig. 5). In the second approach, we selected the closest $N=$ 200 (1932-1974) or $N=500$ (other periods) (Fig. 6) with a maximum radius of $r_{\max }=20 \mathrm{~km}$, which was selected by trial and error. In both approaches, we averaged over space and time to characterize the completeness estimates based on earthquake samples. Areas with insufficient seismicity for the parts of the SCSN reporting region have magnitude completeness levels that are considered to be similar to the detection capability or $M_{\mathrm{c}} \sim 3.25$ from 1932 to 1980 and $M_{\mathrm{c}} \sim 1.8$ from 1981 to present.

In our data analysis approach, a trade-off exists between quality, time period, and volume. The difference in spatial coverage highlights the trade-off between the large data set required for better quality of the completeness estimate and the need for spatial information. To avoid these trade-offs, Schorlemmer and Woessner (2008) introduced a method to estimate the detection capabilities of a seismic network based on empirical data; however, this approach needs more detailed information, such as station recording times and phase picks, which is not available for all the time periods that we analyzed here.

From the mapped completeness estimates, we created cumulative distribution functions (CDF) that depict the improvement of the completeness levels (Fig. 7). The steeper the trend and the more the curve is shifted toward smaller magnitudes (smaller $M_{\mathrm{c}}$ ), the better is the detection capability of the network. The difference between the first and the two successive time periods is the largest, corresponding to the installation of many new seismic stations. The differences between the two sampling approaches are negligible for this analysis. A second important shift to smaller and more homogeneous coverage of southern Californian seismicity is associated with the installation of broadband seismometers and their use in the routine processing in the time period 2001-2008, as the percentage of low completeness levels shows. 
(a)

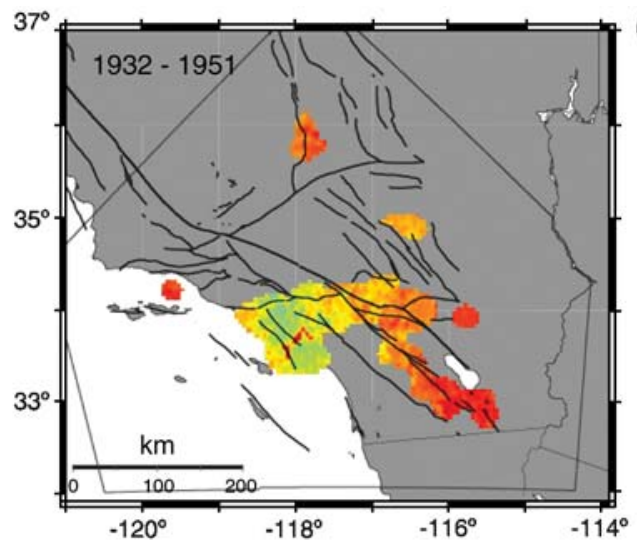

(c)

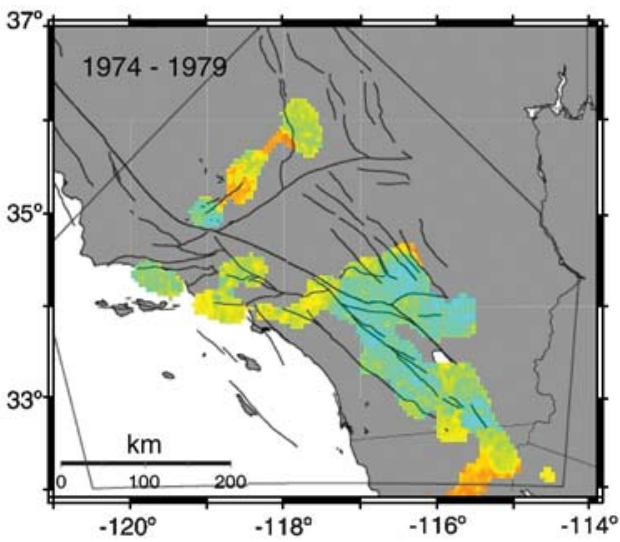

(e)

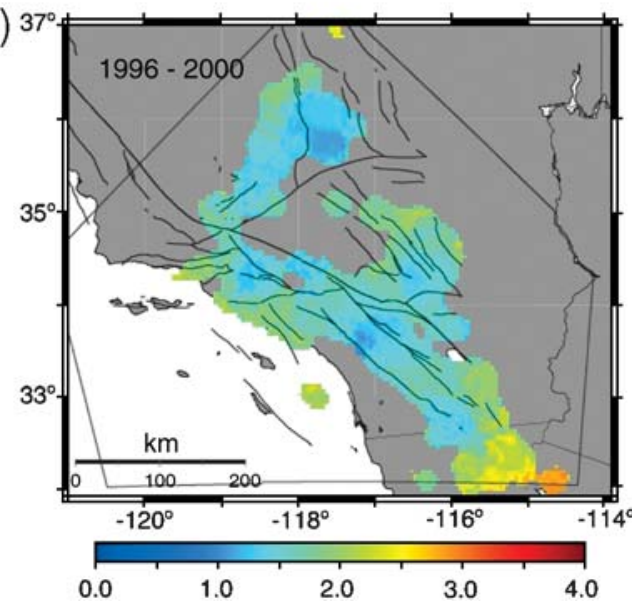

(b)

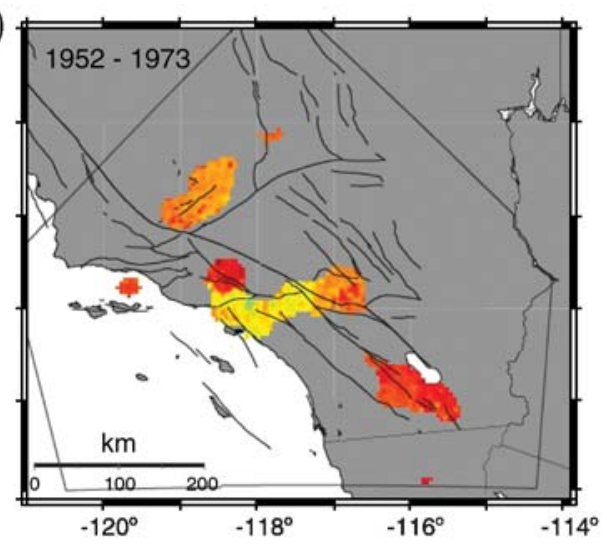

(d)

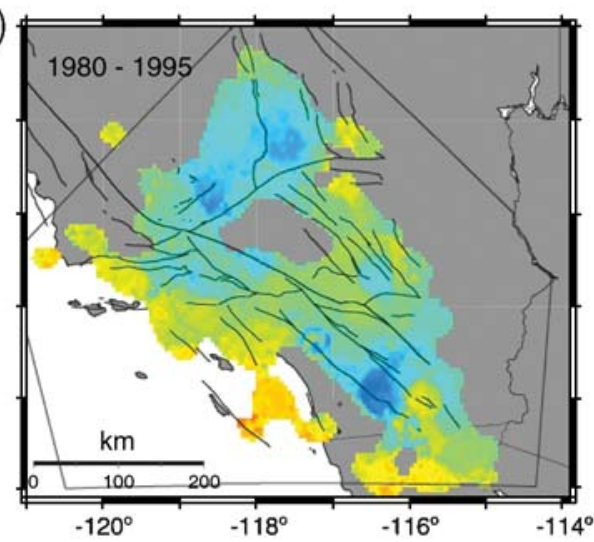

(f)

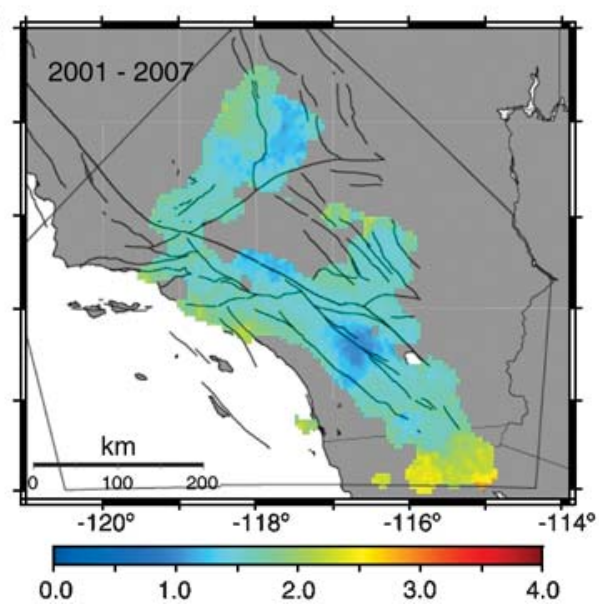

Figure 5. Maps of the magnitude of completeness $M_{\mathrm{c}}$ (EMR), as indicated by colors, for the SCSN catalog divided into six periods: (a) 1932-1951, (b) 1952-1973, (c) 1974-1979, (d) 1980-1995, (e) 1996-2000, and (f) 2001-2007. For each node (grid spacing $0.05^{\circ} \times 0.05^{\circ}$ ), earthquakes in a vertical cylinder within a radius of $R=20 \mathrm{~km}$ and shallower than $30 \mathrm{~km}$ are sampled. A minimum of $N=$ 100 events is required. Coverage, homogeneity, and the threshold level improve spatially but vary with time. The magnitude completeness level for the parts of the SCSN reporting region with insufficient data is considered to be $M_{\mathrm{c}} \sim 3.25$ from 1932 to 1980 and $M_{\mathrm{c}} \sim 1.8$ from 1981 to present.

The spatial coverage through time is a function of the seismic station density and network procedures. Some data from individual sequences in the early period, as, for example, the 1933 Long Beach earthquake on the Newport-Inglewood fault, improved the level of completeness in comparison to surrounding areas to an anomalously high level, simply due to proximity to some of the operating seismic stations.
In the period 1932-1952, the offshore region along the Newport-Inglewood fault (southern end around $-117^{\circ} \mathrm{W} /$ $33.6^{\circ} \mathrm{N}$ ) had a difference of

$$
\Delta M_{\mathrm{c}}(\mathrm{EMR})=M_{\mathrm{c}}(R=20 \mathrm{~km})-M_{\mathrm{c}}(\text { ConstNum }) \approx-1.5
$$

(Figs. 5 and 6). This example actually points to a drawback of obtaining a larger coverage by using less stringent 
(a)

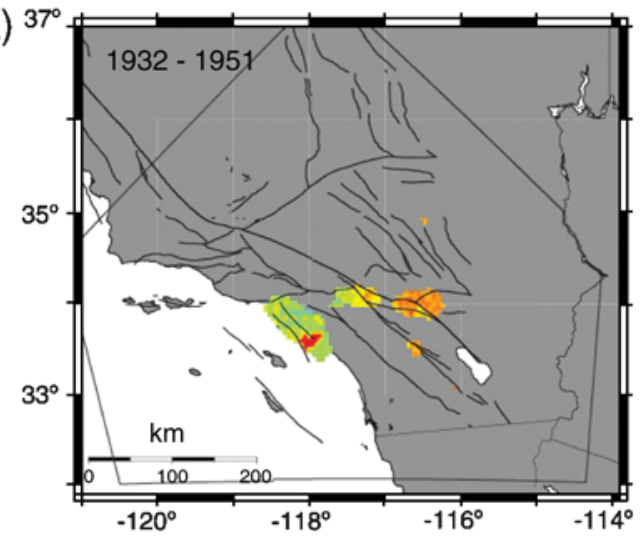

(c)

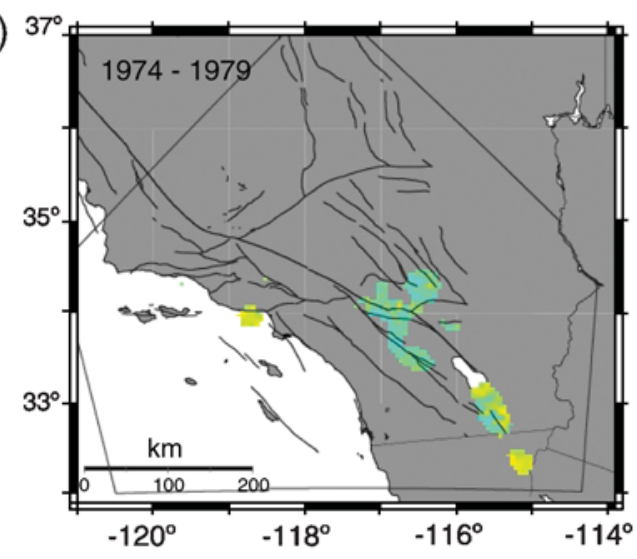

(e)

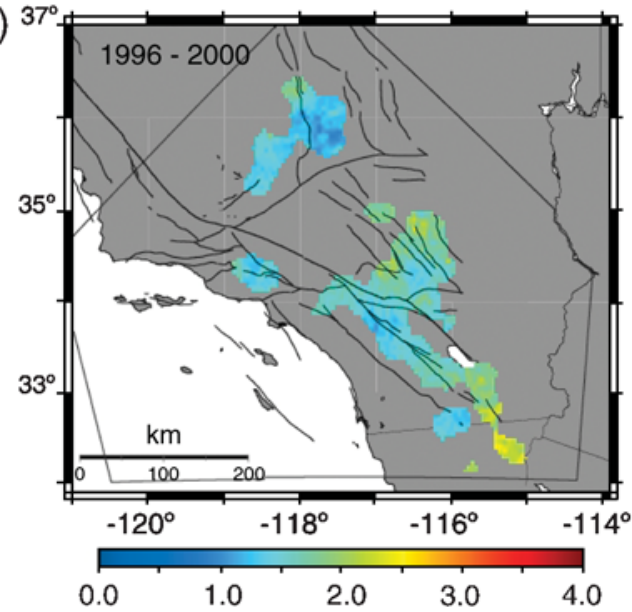

(b)

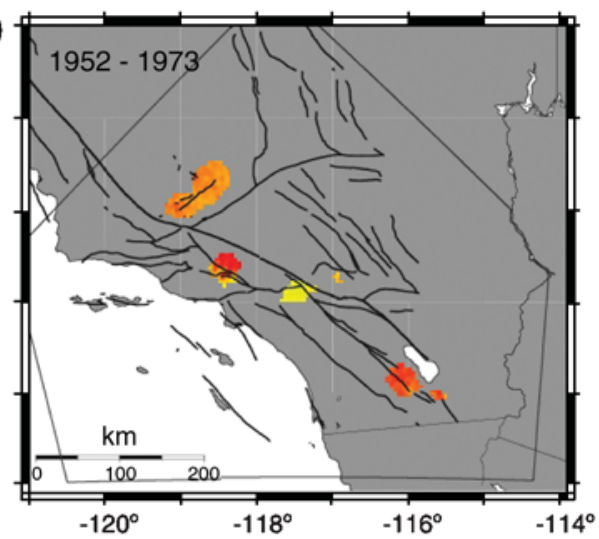

(d)

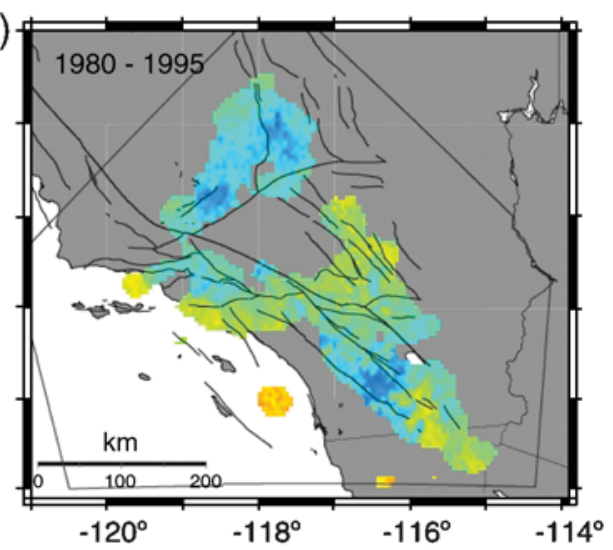

(f)

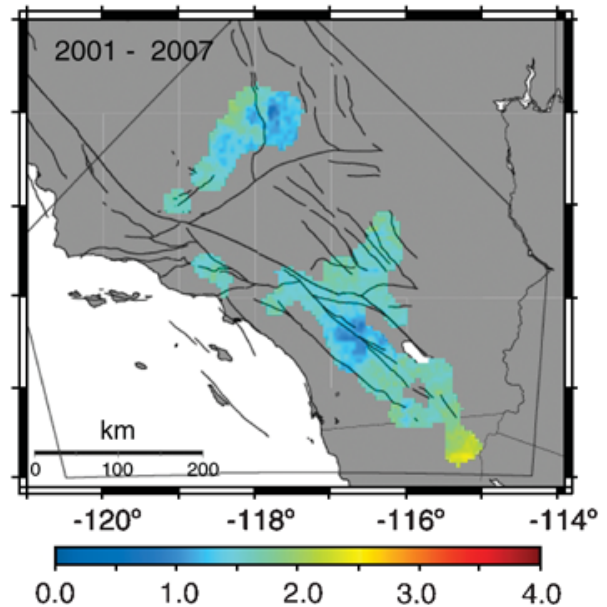

Figure 6. Maps of the magnitude of completeness $M_{\mathrm{c}}$ (EMR), as indicated by colors, for the SCSN catalog divided into six periods: (a) 1932-1951, (b) 1952-1973, (c) 1974-1979, (d) 1980-1995, (e) 1996-2000, and (f) 2001-2007. For each node (grid spacing $0.05^{\circ} \times 0.05^{\circ}$ ), earthquakes of a constant number of $N=200$ and shallower than $30 \mathrm{~km}$ are sampled in the first three periods and $N=$ 500 in the following three periods. Coverage, homogeneity and the threshold level improve spatially but vary with time. When compared to Figure 5, the coverage is smaller because of the different data requirements. The magnitude completeness level for the parts of the SCSN reporting region with insufficient data is considered to be $M_{\mathrm{c}} \sim 3.25$ from 1932 to 1980 and $M_{\mathrm{c}} \sim 1.8$ from 1981 to present.

requirements on the number of samples. The 1952-1972 period has the smallest spatial coverage and, in comparison to the other periods, shows the highest completeness values. The largest difference in the spatial coverage, between the two different mapping approaches, is found in the period 19731979, as a consequence of the differing amounts of data required. In the areas for which both estimates are obtained, the values are similar.
Starting with the 1980-1995 period, the seismic network began to improve significantly. For this period, we obtain the lowest completeness levels $\left(M_{\mathrm{c}} \leq 1.6\right)$ in regions north of the Garlock fault, in the Coso region, in the area of 1994 Northridge earthquake, along the Elsinore and San Jacinto fault systems, and in the Mojave section along the faults that ruptured during the 1992 Landers earthquake. The Los Angeles basin shows mainly values of $M_{\mathrm{c}} \geq 1.8$ 
(a)

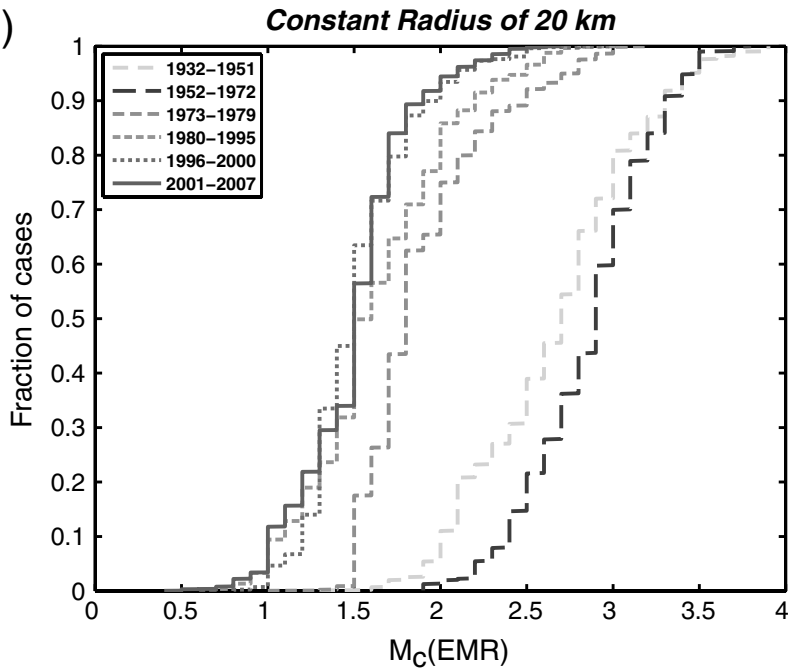

(b)

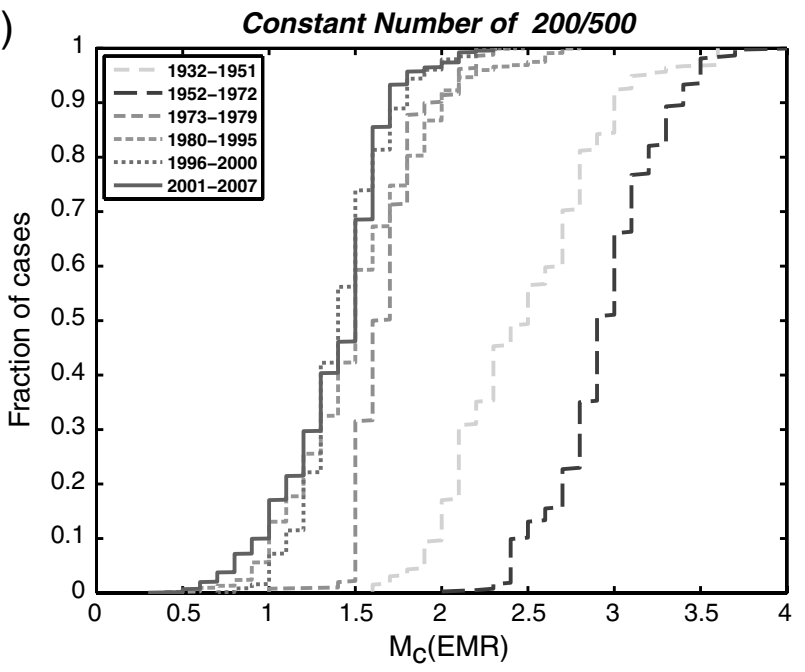

Figure 7. (a) CDF of $M_{\mathrm{c}}$ (EMR) for the different periods using a constant radius of $20 \mathrm{~km}$. The CDF move to the left showing the improvement of the completeness level with time. In the earliest period, the completeness level is about $M_{\mathrm{c}} \leq 3.0$ for $90 \%$ of the grid nodes. In the latest period, this level is at $M_{\mathrm{c}} 1.5$. (b) CDF of $M_{\mathrm{c}}$ (EMR) for the different periods using a constant-number sampling. The CDF move to the left showing the improvement of the completeness level for the later periods. In the earliest period, the completeness level is about $M_{\mathrm{c}} \leq 3.1$ (2.7) for $90 \%$ of the grid nodes. In the latest period, this level is at $M_{\mathrm{c}} 1.5$.

due to the higher cultural noise levels. These patterns are observed in both approaches. Similarly, the offshore areas and the areas in Mexico are characterized by the highest $M_{\mathrm{c}}$ values, in this case due to sparse station coverage.

In the periods 1996-2000 and 2001-2007, the detection threshold improves and becomes more homogeneous with time. The regions of the best completeness values are concentrated around the Anza section of the San Jacinto fault system due to the contribution of the local Anza network.

We summarized the statistics of the completeness estimates for the two approaches by providing a measure of how well the EMR seismicity model fits the observed data
(Table 6). The EMR method generates a comprehensive seismicity model (Woessner and Wiemer, 2005) that is tested against the observed data with a Kolmogorov-Smirnov test (KS test) to examine the goodness of fit (Conover, 1999). The null-hypothesis $H_{0}$ of this test is that the two data sets are drawn from the same distribution. For each test, we obtain a binary result for the KS test at the 0.05 significance level. If $H_{0}$ is not rejected, the theoretical seismicity model does comply with the observed seismicity. If $H_{0}$ is rejected, the theoretical model does not fit the observed data. The percentages for not rejecting $H_{0}$ are very high (above 95\%) for all cases except for the period 1980-1995 (83.2\%) (Table 6) using the constant radius approach. The approach using a constant number of events leads to high values of nonrejection, as a sufficient amount of data is required, with the drawback of a smaller spatial coverage. The smaller percentage for the constant-number approach, in the period 1980-1995, results from the 1992 Landers earthquake sequence. Many events are sampled at the single grid nodes, which effects the KS statistic as it becomes more restrictive. Using a significance level of 0.05 leads to more rejections. However, at a slightly less rigorous significance level, the percentage of rejection would be strongly reduced.

In a study by K. Z. Nanjo, D. Schorlemmer, J. Woessner, S. Wiemer, and D. Giardini (unpublished manuscript, 2009), a thorough comparison between the Schorlemmer and Woessner (2008) probabilistic magnitude of completeness (PMC) method and the EMR method (Woessner and Wiemer, 2005) is performed. The result for the case of the Swiss Seismic Network and catalog is that the PMC method produces higher values for the space-time volumes compared. Such a comparison for southern California would be beneficial and would contain valuable information because the new method better constrains periods with worse detection levels. The EMR method is not able to see the bad periods and tends to highlight periods with the best detection capabilities, thus leading to completeness values that may be too small.

The target magnitude of completeness of AQMS (20012007) is $M_{\mathrm{c}} 1.8$ (Hauksson et al., 2001). Our analysis shows that, at the grid nodes for which we compute the completeness levels, 90\% (95\% for constant number of events) have a completeness level of $M_{\mathrm{c}} 1.8$ or less. Even if both approaches of averaging over space or time underestimate the completeness levels, most of the $M_{\mathrm{c}}$ values would still be $\sim 1.8$. The constant-number sampling approach performed slightly better in this sense, because a larger numbers of events are aggregated.

\section{Transitions in the Catalog}

To illustrate both man-made and natural temporal changes in the catalog, we plotted the magnitudes of all events as a function of time since 1932 (Fig. 8). This plot reveals anomalies in the catalog related to (1) individual sequences that may be located in areas of station density higher 
Table 6

Summary of Results from the Completeness Maps

\begin{tabular}{|c|c|c|c|c|c|c|}
\hline \multirow[b]{2}{*}{ Period } & \multicolumn{2}{|c|}{ Number of Nodes Computed ${ }^{*}$} & \multicolumn{2}{|c|}{ EMR Model Accepted ${ }^{\dagger}$} & \multicolumn{2}{|c|}{ Percentage Accepted by KS Test } \\
\hline & $R=20 \mathrm{~km}$ & Constant Number & $R=20 \mathrm{~km}$ & Constant Number & $R=20 \mathrm{~km}$ & Constant Number \\
\hline $1932-1951$ & 1297 & 393 & 1282 & 380 & 98.8 & 96.7 \\
\hline $1952-1972$ & 1025 & 374 & 1008 & 369 & 98.8 & 96.7 \\
\hline 1973-1979 & 2170 & 498 & 2084 & 460 & 96.0 & 92.3 \\
\hline 1980-1995 & 5042 & 2978 & 4197 & 2877 & 83.2 & 96.6 \\
\hline 1996-2000 & 3396 & 1586 & 3281 & 1563 & 96.6 & 98.5 \\
\hline 2001-2007 & 3245 & 1700 & 3115 & 1688 & 95.9 & 99.2 \\
\hline
\end{tabular}

Maps are displayed in Figures 5 (constant $R=20 \mathrm{~km}$ ) and 6 (constant number).

*The number of the nodes at which an $M_{\mathrm{c}}$ (EMR) estimate is computed.

The number of nodes the EMR model is accepted by the KS test at the 0.05 significance level.

The percentage of the nodes at which the model is accepted.

than the average, such as the 1933 Long Beach sequence; (2) possible changes in analysis practice, such as that following the 1952 Kern County mainshock; and (3) occurrence of major sequences, such as the 1992 Landers sequence.

During the past three decades of technological improvements, either the detection or the magnitude assignment for the smaller earthquakes has been somewhat uneven, leading to a time varying $M_{\mathrm{c}}$ (Fig. 8). However, there may not be fewer earthquakes in the less shaded regions because the dots overlap during time periods when magnitudes were assigned only to nearest 0.1 magnitude unit. In contrast, the upper edge of the distribution, corresponding to the processing of large earthquakes, is noticeably smoother except for individual aftershock sequences.

The presence of a strong aftershock sequence or a large swarm affected the detection level and the data processing procedures (e.g., Kilb et al., 2007). One example is the absence of small cataloged aftershocks following the 1952 Kern County earthquake, although an attempt was made to catalog all detected earthquakes occurring outside the aftershock zone (Richter, 1958). There was an abrupt increase in the detection level on 1 November 1952, reflecting changes in catalog procedures, when cataloging of all detected Kern County aftershocks resumed. The catalogs for 1992 Landers and 1999 Hector Mine earthquake sequences also show a similar degradation but only for a few days, rather than months. This degradation is most likely due not to procedural changes but to confusion in the triggering algorithms, as continued high signal level raised the longterm average, thus desensitizing the triggering algorithm. In addition, both analysts and automatic pickers typically find it difficult to identify good picks in waveforms from numerous aftershocks that overlap in time.

The following operational changes, many of which are annotated in Figure 8, probably affected the quality of the catalog:

1. The change from develocorder to digital recording (1977), from CEDAR to CUSP recording and analysis (1981), and from CUSP to TriNet/AQMS processing (2001) caused changes in the number of earthquakes with different types of magnitudes.

2. In 1986, the gains of the short-period instruments were deliberately changed to decrease the network sensitivity, which resulted in fewer small earthquakes being detected and entered into the catalog.

3. Broadband synthetic Wood-Anderson amplitudes were analyzed concurrently with the actual Wood-Anderson amplitudes beginning in 1987 and ending in 1992, when the physical Wood-Anderson instruments were retired. At this time the Wood-Anderson gain was assumed to be the nominal 2800, rather than 2080 (see previously). The amplitudes have been corrected in the database, but the magnitudes, which result from a combination of real and synthetic amplitudes, remain to be corrected. For this reason, a more or less gradual change is expected in the late 1980s and in 2003, when the correct gain went into use.

4. With the introduction of synthetic Wood-Anderson amplitudes, there was a change in the specification for amplitude measurement. On drum recordings, the amplitude was measured as one-half the total range of the largest identifiable single swing of the trace. On the digital records up until 1 January 2008, however, amplitude is the peak deviation from the mean value.

5. The introduction of synthetic Wood-Anderson amplitudes in the early 1990s with higher dynamic range allowed computation of more $M_{\mathrm{L}}$ values, so that fewer $M_{\mathrm{ca}}$ and $M_{\mathrm{h}}$ values were necessary.

6. Starting in $1932 M_{\mathrm{w}}$ was the preferred magnitude for $M \geq 6.0$, and beginning in $2000 M_{\mathrm{w}}$ became the preferred magnitude for $M \geq 5.0$.

7. Problems are expected in the magnitude range $2.0-3.5$ in the $1980 \mathrm{~s}$ and $1990 \mathrm{~s}$, where many assigned $M_{\mathrm{ca}}$ may be overestimates and the $M_{\mathrm{ca}}$ scale needs to recalibrated.

8. In 2008 , the $M_{\mathrm{L}}$ algorithm was changed to a new statewide attenuation function and set of station corrections, with the capability of $M_{\mathrm{L}}$ computation for very small earthquakes riding on long-period signals. Prior to that time, most of the smallest earthquakes have $M_{\mathrm{h}}$ magnitudes based on a 


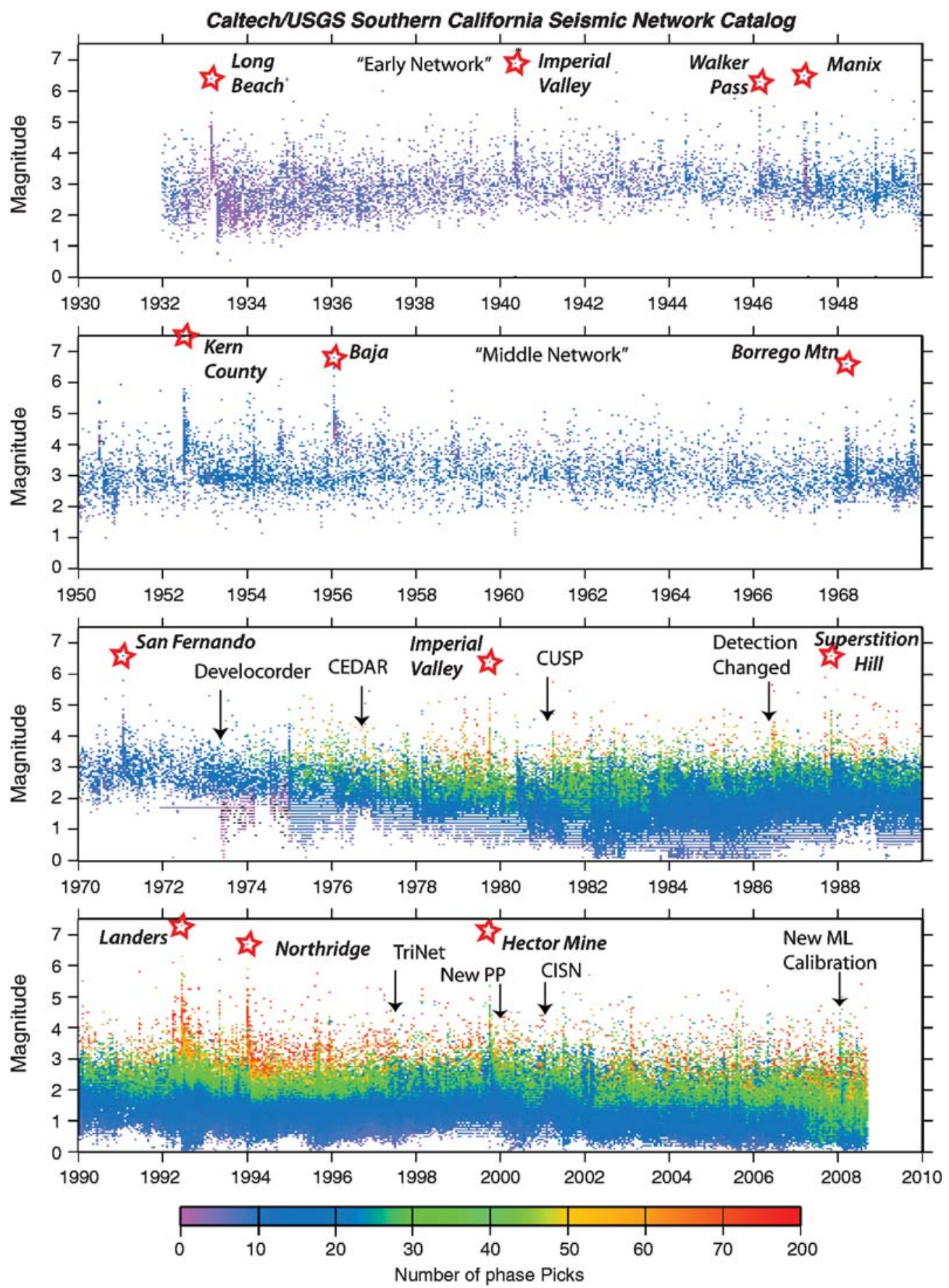

Figure 8. The preferred magnitudes of more than 470,000 earthquakes are shown as a function of time, revealing possible changes in both operational procedures and in seismicity rate through SCSN history. The color, which is adjusted to cover similar areas in the plot, shows the number of phase picks as a function of time. The dates of major earthquakes and network changes are annotated.

visual estimate of event duration, or the $M_{\mathrm{L}}$ values were overestimated because the amplitudes may have included long-period energy.

The times of many of these potential catalog break points are annotated in Figure 8. The maintenance of a continuous earthquake catalog through technological changes is a complex process, but one that must be addressed if the new technological advantages are to be incorporated.

\section{Southern California Seismicity}

During the past $77 \mathrm{yrs}$, the SCSN has recorded more than 470,000 earthquakes (Fig. 9). Most of these events were detected in the past two decades because more stations were 
(a)

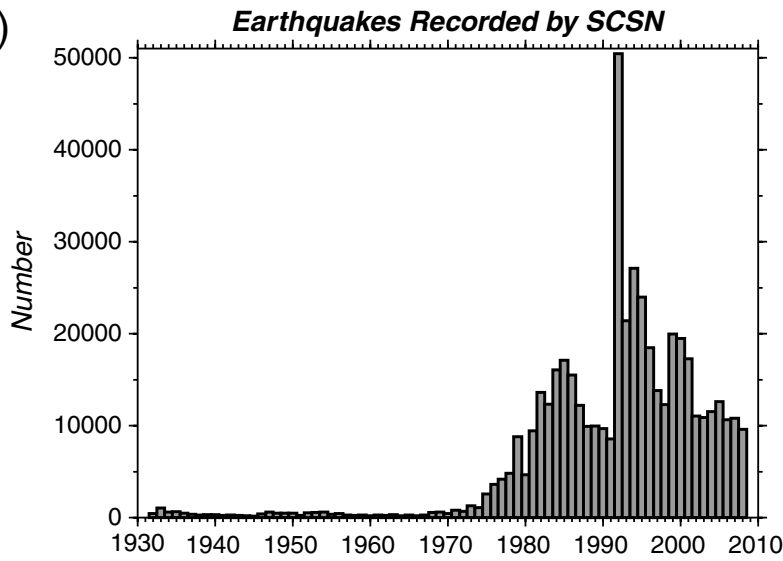

(b)

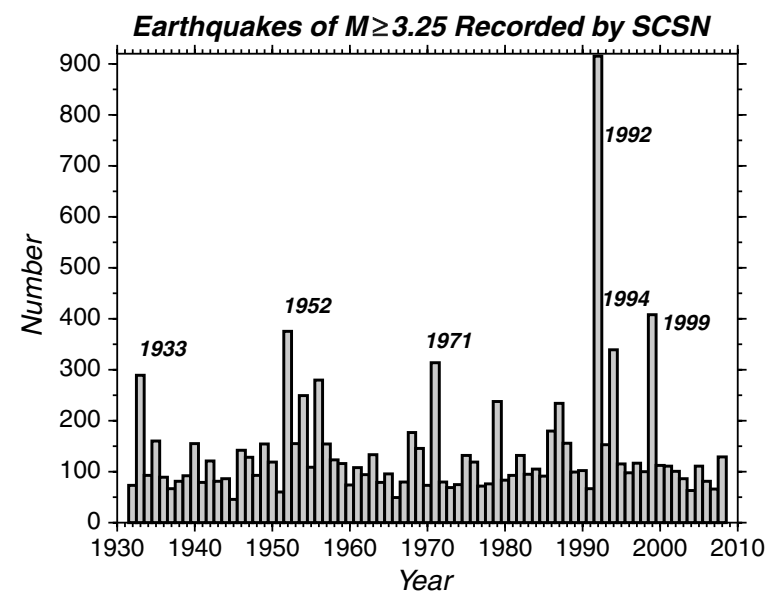

Figure 9. (a) Histogram of the total number of earthquakes as a function of time. Each bin holds $1 \mathrm{yr}$ of data. (b) Histogram of earthquakes of $M \geq 3.25$, with major mainshocks labeled by year. The 1952 (Kern County $M_{\mathrm{w}}$ 7.5) column is underestimated because many of the $M \geq 3.25$ aftershocks were not cataloged during the first few weeks of the sequence.

deployed, data processing procedures improved, and the $1992 M_{\mathrm{w}} 7.3$ Landers, the $1994 M_{\mathrm{w}} 6.7$ Northridge, and the $1999 M_{\mathrm{w}} 7.1$ Hector Mine sequences occurred. However, the number of $M \geq 3.25$ events has remained similar throughout the whole time period, except for increased activity during large aftershock sequences (Fig. 9). Thus, the earthquake monitoring capabilities for moderate-sized or large events $\left(M_{\mathrm{c}} \geq 3.25\right)$ have remained similar since the 1930s.

\section{Seismicity Patterns}

The seismicity of $M \geq 3.25$ recorded by the SCSN from 1932 to present is dominated by the $M \geq 6$ mainshock-aftershock sequences (Fig. 10). Within the network, the aftershocks form dense distributions outlining the mainshock rupture zones, while individual swarms also form dense clusters. More scatter in the locations is evident on the edges and outside the network, particularly offshore in the Continental Borderland and in northern Baja. Nonetheless, the SCSN is capable of adequately recording events of $M \geq$ 3.25 up to $100-150 \mathrm{~km}$ distance from its edges.

The three largest earthquake sequences that were recorded, $1952 M_{\mathrm{w}} 7.5$ Kern County, $1992 M_{\mathrm{w}} 7.3$ Landers, and $1999 M_{\mathrm{w}} 7.1$ Hector Mine, occurred to the east of the San Andreas fault, in the Tehachapi Mountains, and the eastern Mojave Desert. All three mainshocks were followed by tens of kilometers long, as well as long lasting, aftershock sequences that continue today. The three most damaging earthquakes, the $1933 M_{\mathrm{w}} 6.4$ Long Beach, $1971 M_{\mathrm{w}} 6.7$ San Fernando, and $1994 M_{\mathrm{w}} 6.7$ Northridge earthquakes, occurred in the greater Los Angeles area. On the average a mainshock-aftershock sequence with an $M \geq 6$ mainshock occurs approximately every 3 yrs in southern California.

Since 1981, with the dense network and modern data processing capabilities the seismicity distributions are more spatially clustered (Fig. 11). Numerous trends of seismicity form broad distributions around the mapped late Quaternary faults (Hauksson, 2010). In a few cases, in areas where there are no mapped late Quaternary faults, the seismicity trends may form apparent linear features. Some examples of such lineations are orthogonal trends to the west of the San Jacinto fault, which suggest conjugate faulting perpendicular to, rather than parallel to, the San Jacinto and other northweststriking faults, as observed by Nicholson et al. (1986). Similarly, the northeast trending seismicity that crosses the southern Sierra Nevada is not associated with specific late Quaternary faults.

Although the San Andreas fault is the main plate boundary fault in the southern California region, and probably carries at least $60 \%$ of the tectonic offset (Weldon and Humphreys, 1986), most of the earthquakes recorded during the operation of the SCSN occurred on other faults. Previous authors, for example, Wood (1947a,b), Allen et al. (1965), Hill et al. (1990), and Hutton et al. (1991), have remarked on the spatially more complex distribution of seismicity in southern California, as compared to northern California, which in part is related to the more westerly strike of the San Andreas fault in southern California. This complexity results in several 3D distributions of seismicity that extend to the west from the San Andreas fault into the Los Angeles and Ventura basins. The Landers (Hauksson et al., 1993) and Hector Mine (Hauksson et al., 2002) mainshocks exhibited another example of faulting complexity by linking together multiple mapped faults into single mainshock ruptures. Page et al. (2009) have noted that the San Andreas fault seismicity appears to follow the Gutenberg-Richter distribution of magnitudes. They suggest that the observed lack of small earthquakes on the main fault plane may indicate that some of the largest earthquakes nucleate off of the San Andreas fault and rupture onto it via linked faults.

\section{SCSN Earthquake Statistics}

From the SCSN catalog, we compute the rate of earthquakes in southern California since 1932. The average 


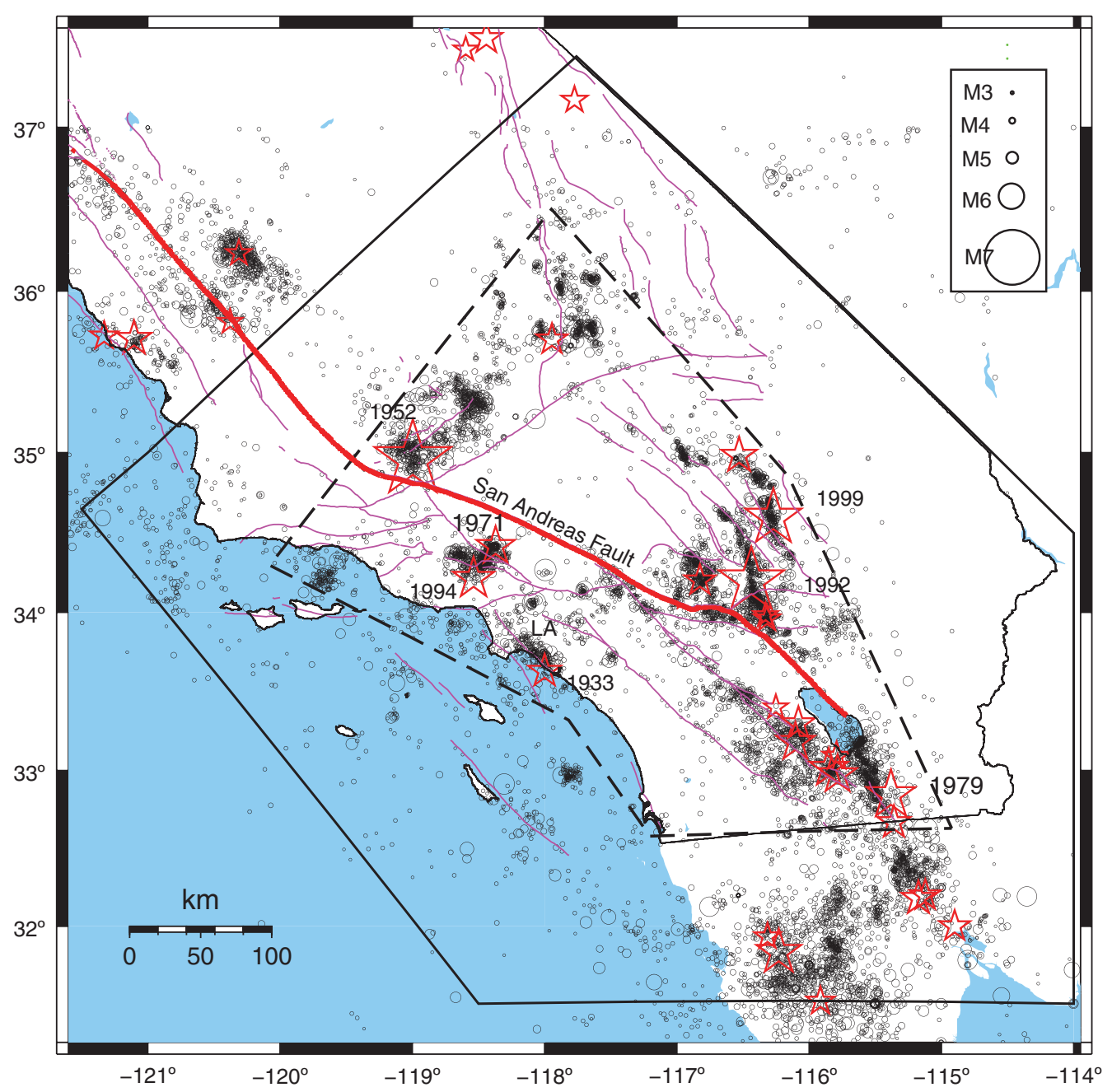

Figure 10. Map of the $M \geq 3.25$ seismicity from 1932 to 2008 . The size of the symbol scales with magnitude. Late Quaternary faults are from Jennings (1995). The boundary of the SCSN coverage area (outer polygon with solid border) is also included. The inner polygon (dashed border) indicates the area used in this article for the $b$-value statistics presented in Figures 13, 14, and 15. Earthquakes with $M \geq 6$ are shown as stars and labeled by years. See the caption of Figure 1 for place names and the names of earthquakes labeled by years (e.g., 1933, Long Beach; LA, Los Angeles).

annual rate of earthquakes recorded, both including aftershocks and without aftershocks (declustered), is shown in Table 7. We declustered the catalog by applying the method described by Reasenberg (1985), and Reasenberg and Jones (1989), to the SCSN catalog events with $M \geq 2.95$ (which would round to $M \geq 3.0$ ). The results were relatively independent of the declustering parameters, and we chose values in the middle of the range of acceptable values: $\tau_{0}=\tau_{\min }=7$ days, $\tau_{\max }=6$ months, and distance correlation parameter $R=6.0$. Declustering of the catalog for earthquakes of $M \geq 2.95$ show that foreshocks and aftershocks account for approximately $48 \%$ of the earthquakes. On average, an earthquake with $M \geq 6.95$ (which will round up 7.0 or larger) is expected within the coverage region approximately every $25.7 \mathrm{yrs}$, and $M \geq 5.95$ earthquakes are expected at a rate of about once every 2.75 yrs. The declustered rate of $M \geq 5.95$ earthquakes is approximately once every 4.05 yrs. Although Wood (1916) was not specific about what he expected the seismic network to uncover in its future research that would help assess the public earthquake risk, these numbers, the earthquake rates, are clearly among those needed.

The seismicity rate depends strongly on the temporal evolution of the $M_{\mathrm{c}}$ and $b$-value. The average $M_{\mathrm{c}}$ over time remained stable at $\sim 3.25$ from the 1930 s until the early 1970 s (except for major aftershock sequences), when it decreased with time, reaching a lower level of $\sim 1.8$ in the early $1980 \mathrm{~s}$ (Fig. 12). The decrease in $M_{\mathrm{c}}$ reflects mostly the increase in station density since the early 1970s. Some of the short-term fluctuations in the $M_{\mathrm{c}}$ are caused by major mainshock-aftershock sequences. The reduction in the gain of all stations in the network in the mid-1980s is also reflected in a higher $M_{\mathrm{c}}$ value. Thus, the temporal evolution of the $M_{\mathrm{c}}$ value reflects the ability of the network to consistently detect earthquakes rather than a real change in the rate of seismicity. 


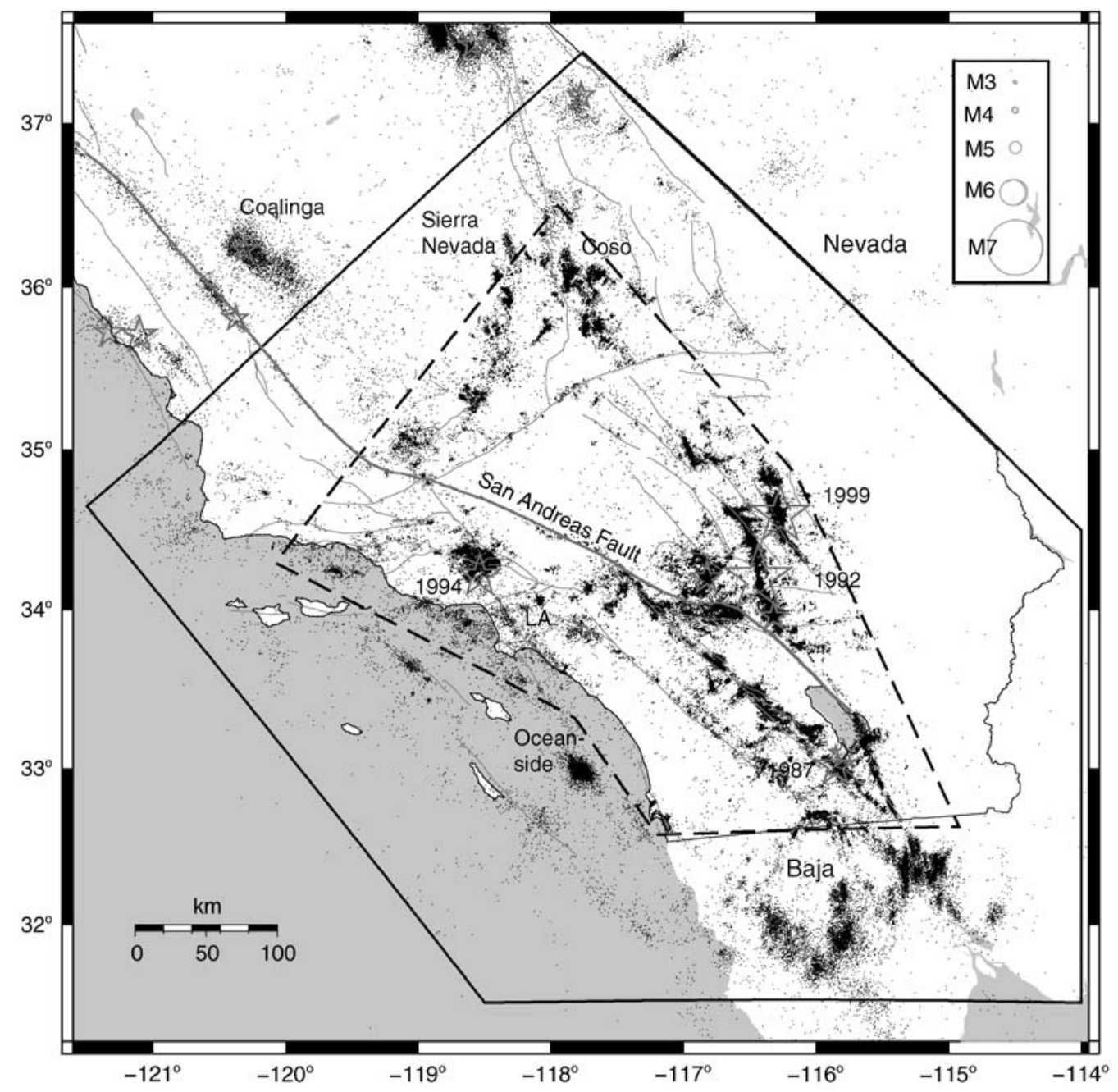

Figure 11. Map of the $M \geq 1.8$ seismicity from 1981 to 2008 . Earthquakes with $M \geq 6$ are shown as stars. Late Quaternary faults are from Jennings (1995). The polygons are the same as in Figure 10.

Similarly, the network average Gutenberg-Richter $b$-value has remained about 1.0 since the 1930 s, when the approach of Wiemer (2001) is applied. To determine the long-term trends in the $b$-value, we divided the catalog into three time periods, 1932-1980, 1954-1980, and 1981-2008. The $b$-value versus magnitude plot for the first time period shows that the preferred $M_{\mathrm{c}}$ is $\sim 4.2$ (Fig. 13). Because this period is strongly influenced by possible incompleteness during the first two decades, and possible missed aftershocks during the $M_{\mathrm{w}} 7.5$ Kern County sequence, a large $M_{\mathrm{c}}$ value is expected. The sudden dip in the $b$-value that coincides with the 1952 sequence is almost certainly due to catalog incompleteness. Fluctuations seen for larger $M_{\mathrm{c}}$ may result from the statistics of small numbers and from magnitude inconsistencies with the larger events. The second time period, excludes the first 2 yrs of the 1952 sequence and has a significantly lower $M_{\mathrm{c}} \sim 3.0$ (Fig. 14). The $b$-value is well constrained through more reliable catalog data and is also more stable over time, in part because no large mainshock-aftershock sequence occurred. The third time period includes almost
30 yrs of the modern catalog. The $b$-value reaches a value of 1.0 at $M_{\mathrm{c}} 1.8$ because of the improve sensitivity of the seismic network (Fig. 15). The $b$-value versus $M_{\mathrm{c}}$ plot exhibits an

Table 7

Average Earthquake Rates Based on the Seismicity Catalog Recorded by the SCSN for 1932 through 2008

\begin{tabular}{cccc}
\hline $\begin{array}{c}\text { Magnitude } \\
\text { Range }\end{array}$ & $\begin{array}{c}\text { Number of } \\
\text { Events }\end{array}$ & $\begin{array}{c}\text { Number of } \\
\text { Events/Yr }\end{array}$ & $\begin{array}{c}\text { Average } \\
\text { Recurrence Rate }\end{array}$ \\
\hline \multicolumn{4}{c}{ Average Earthquake Rates } \\
$3.0+$ & 19,707 & $\sim 256 / \mathrm{yr}$ & $1 / 1.4$ days \\
$4.0+$ & 2485 & $32.3 / \mathrm{yr}$ & $1 / 11.3$ days \\
$5.0+$ & 253 & $3.29 / \mathrm{yr}$ & $1 / 111$ days \\
$6.0+$ & 28 & $\sim 0.36 / \mathrm{yr}$ & $1 / 2.75 \mathrm{yrs}$ \\
$7.0+$ & 3 & $\sim 0.039 / \mathrm{yr}$ & $1 / 25.7 \mathrm{yrs}$ \\
5 & Average Declustered $\mathrm{Rates}$ \\
$4.0+$ & 881 & $11.4 / \mathrm{yr}$ & $1 / 31.9$ days \\
$5.0+$ & 104 & $1.35 / \mathrm{yr}$ & $1 / 270$ days \\
$6.0+$ & 19 & $0.25 / \mathrm{yr}$ & $1 / 4.05 \mathrm{yrs}$ \\
$7.0+$ & 3 & $0.039 / \mathrm{yr}$ & $1 / 27 \mathrm{yrs}$ \\
\hline
\end{tabular}

Here magnitudes are rounded to the nearest tenth, that is, there are 28 local earthquakes with $M \geq 5.95$ in the catalog. 


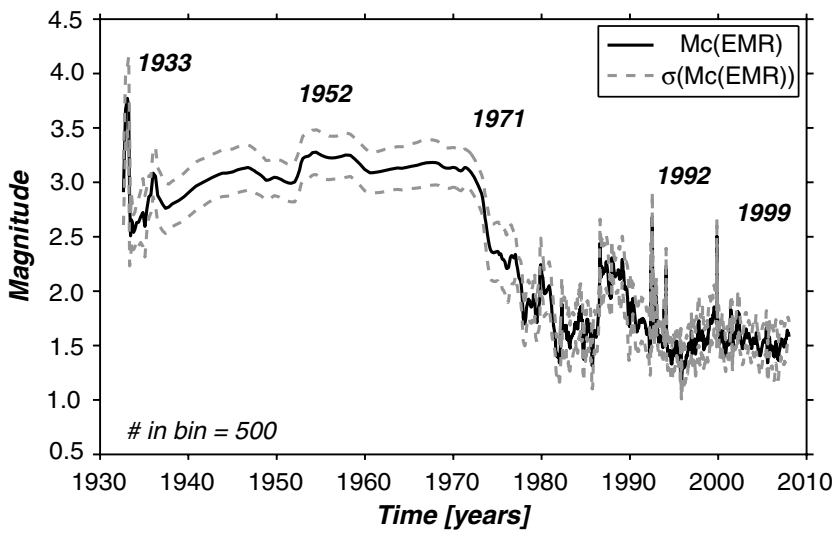

Figure 12. $M_{\mathrm{c}}$ estimated using the EMR method as a function of time using the method of Woessner and Wiemer (2005). One sigma error bars are shown.

anomalous increase in $b$-value for $M_{\mathrm{c}}$ between 1.8 and about 3.0. This anomaly could be the result of a miscalibration of the coda-duration $\left(M_{\mathrm{ca}}\right)$ magnitudes or unstable small $M_{\mathrm{L}}$ values caused by long-period noise in the broadband waveforms, which are being addressed. The use of the $M_{\mathrm{ca}}$ magnitudes was discontinued at the beginning of 2001 because the new digital stations provided sufficient amplitudes to determine $M_{\mathrm{L}}$. Although the network sensitivity is the best ever, low $b$-value estimates can still be seen marking the major sequences, indicating missed events during the early parts of these sequences. These results illustrate how well a network $b$-value can or cannot be constrained over decades. On shorter time scales, when station density and processing techniques remain the same, the $b$-value shows less variability.

There are several ways of determining $b$-values and $M_{\mathrm{c}}$. Here we have chosen to follow Felzer and Cao (2008) and use conservative $M_{\mathrm{c}}$ values, which correspond to a $b$-value close to 1.0. By using high $M_{\mathrm{c}}$ values, a large fraction of the catalog is not included in the analysis. The final $M_{\mathrm{c}}$ and $b$-values may thus be closer to what would be expected for a declustered catalog and thus would be more representative of the long-term seismicity rate. However, a $b$-value of $\sim 1.0$ appears to underpredict the number of $M>6$ events (Figs. 13a, 14a, and 15a). It is unlikely that this underprediction could be caused by changes in magnitude scale because, for $M>6$, the $M_{\mathrm{L}}$ scale underestimates the size and $M_{\mathrm{w}} \mathrm{s}$ are more representative of the earthquake size than the $M_{\mathrm{L}}$ values. A $b$-value of $\sim 0.9$ would be much more consistent with the observed number of $M>6$ earthquakes. Alternatively, the largest earthquakes that occur on the principal slip surface of major faults may not obey the same statistics as the volumetric regional catalog (Hauksson, 2010).

\section{Discussion}

Wood's vision in 1916 for a seismological laboratory in southern California has come to fruition $90 \mathrm{yrs}$ later, in the (a)

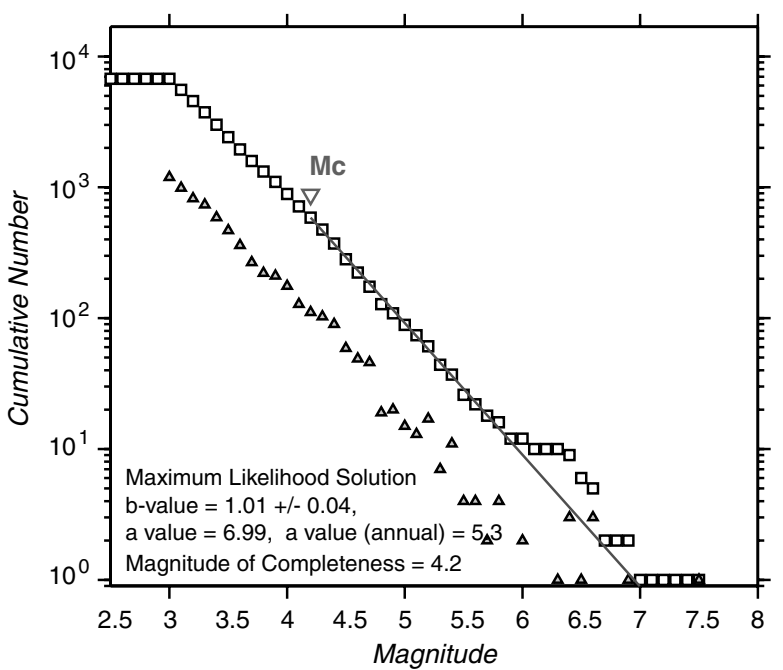

(b)

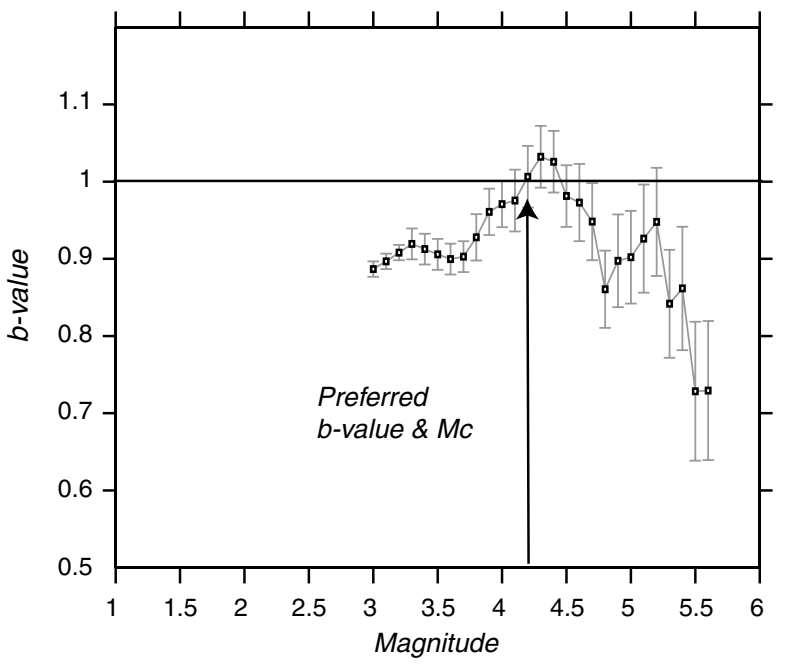

(c)

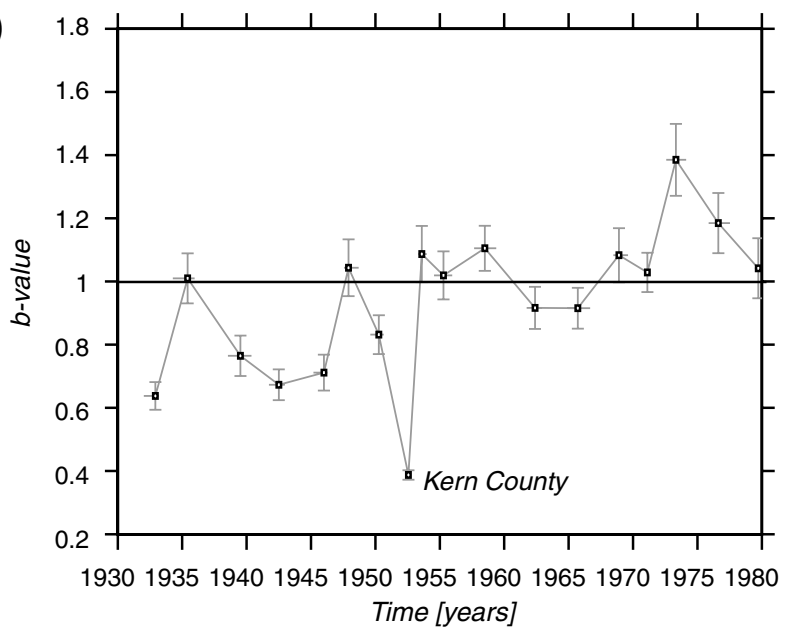

Figure 13. Earthquake statistics for the time period 1932-1980. (a) Cumulative number versus magnitude to determine the $b$-value using a conservative value of $M_{\mathrm{c}} 4.2$ to exclude missing aftershocks during the big sequences. (b) Computed $b$-value estimates as a function of $M_{\mathrm{c}}$ for $M \geq 3$ earthquakes. (c) Computed $b$-values as a function of time from 1932 to 1980 for $M \geq 3$ earthquakes with automatic $M_{\mathrm{c}}$ adjustment. 
(a)

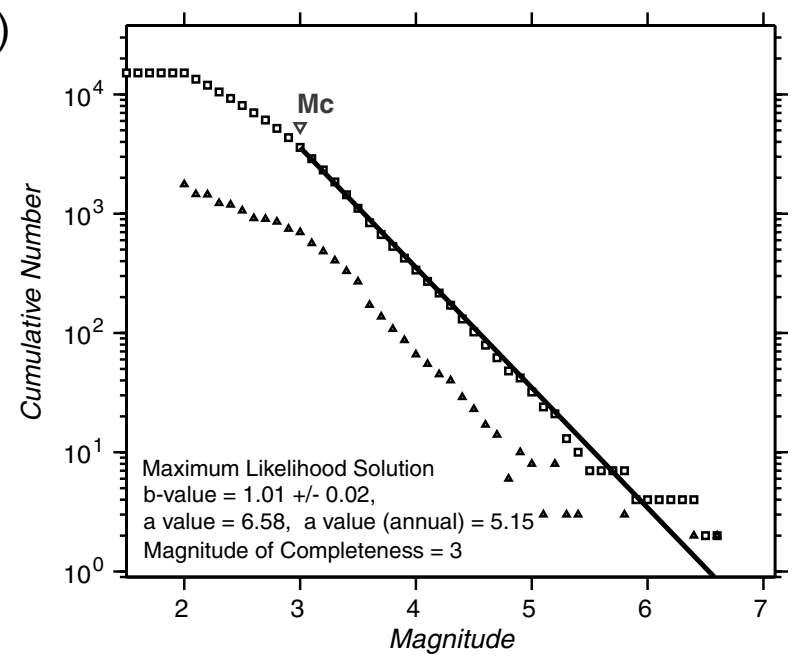

(b)

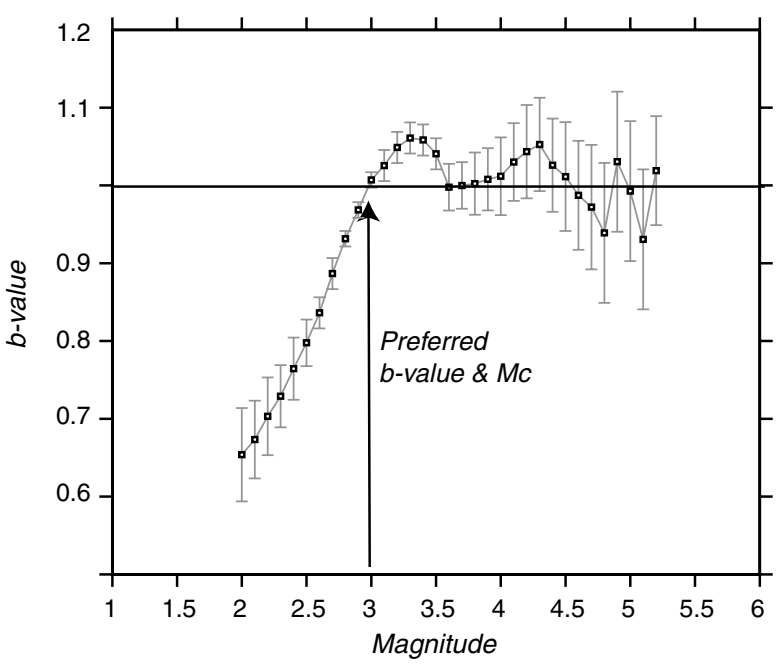

(c)

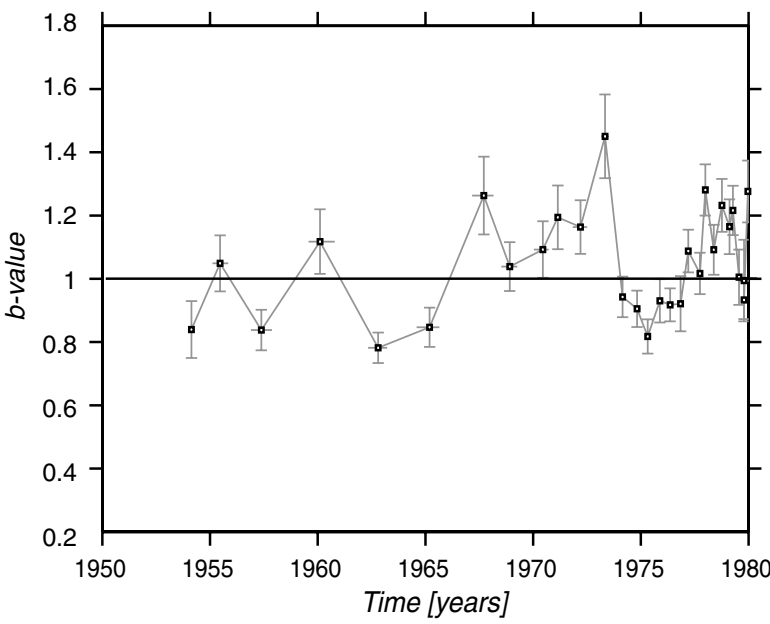

Figure 14. Earthquake statistics for the time period 1954-1980. (a) Cumulative number versus magnitude to determine the $b$-value with a conservative value of $M_{\mathrm{c}}$ 3.0. (b) Magnitude of completeness determined using $M \geq 2.0$ earthquakes during the time period 1952-1979. The preferred $M_{\mathrm{c}}$ is $\sim 3.0$. (c) Computed $b$-values as a function of time from 1952 to 1980 for $M \geq 2.0$ events with automatic $M_{\mathrm{c}}$ adjustment. (a)

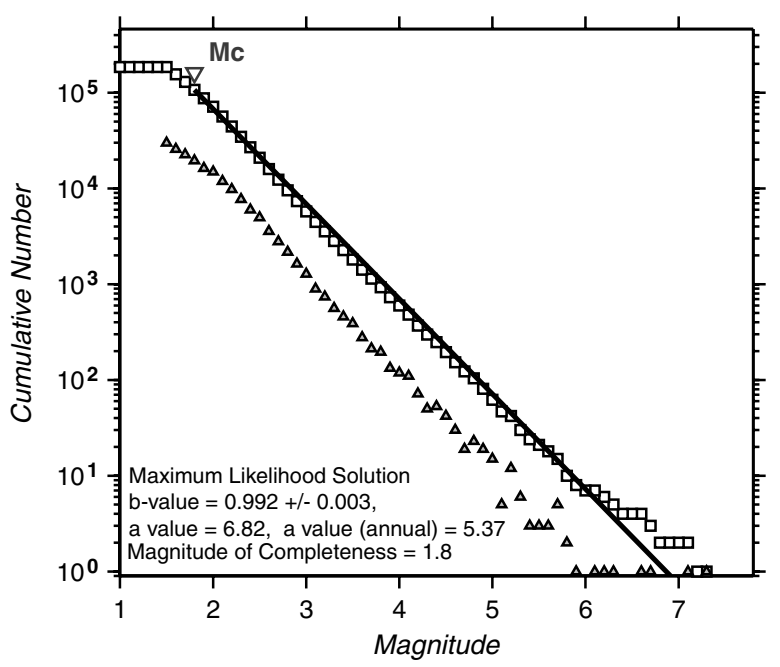

(b)

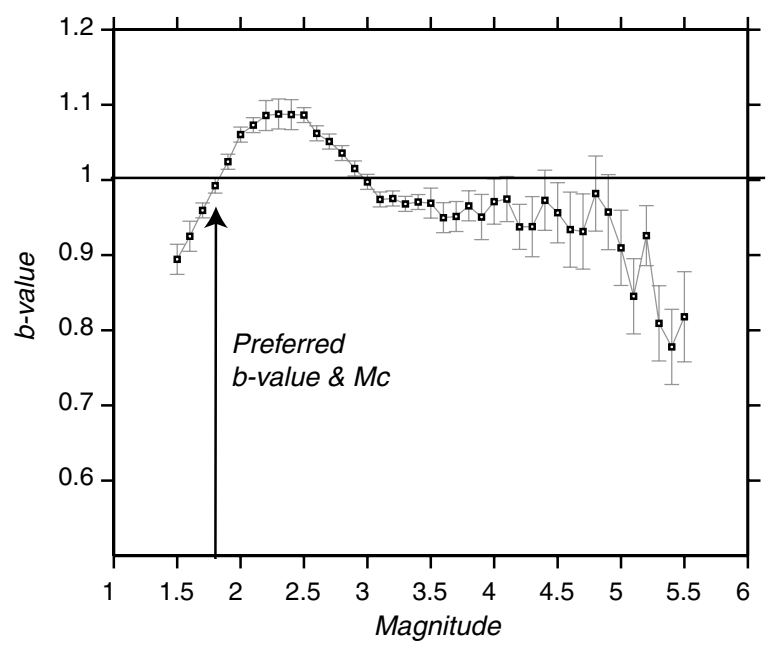

(c)

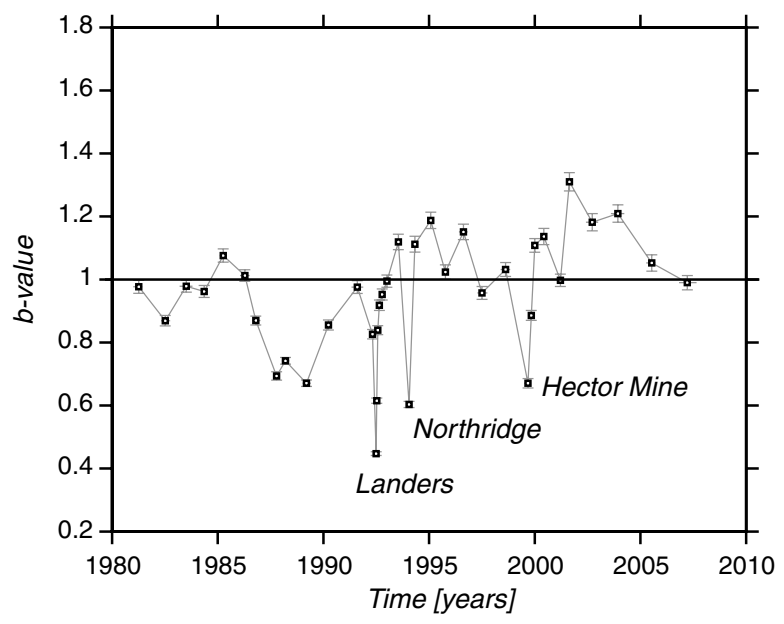

Figure 15. Earthquake statistics for the time period 1981-2008. (a) Cumulative number versus magnitude to determine the $b$-value with a conservative value of $M_{\mathrm{c}} 1.8$ assumed. (b) Magnitude of completeness determined using $M \geq 1.5$ earthquakes during the time period 1980-2008. The preferred $M_{\mathrm{c}}$ is $\sim 1.8$. (c) Computed $b$-values as a function of time from 1980 to 2008 for $M \geq 1.5$ events with automatic $M_{\mathrm{c}}$ adjustment. 
form of the SCSN. Wood's expectations for the seismic network have certainly been fulfilled in terms of the number of stations installed, the number of earthquakes recorded, and the contributions made to the fundamental understanding of earthquake hazards. However, many of his expectations about the relationships between small earthquakes and large earthquakes as well as late Quaternary faulting have not been confirmed. In particular, Wood's ideas about how small earthquakes could be used to predict the spatial and temporal behavior of large earthquakes have not held up. Nonetheless, information has been extracted on the rate of earthquake occurrence in different magnitude ranges (the GutenbergRichter relation), about the geographic distribution of earthquakes relative to the mapped geologic faults, about the crustal structure in the region, and many other geophysical phenomena. Based on these observations, estimates of the earthquake hazard in the densely populated southern California region have been derived. The time period covered (77 yrs) is still less than the average recurrence interval for the largest earthquakes in the region, but it is a significant fraction thereof, longer than for most regional seismic networks.

Similarly, the early observations of Wood (1947a,b), Gutenberg and Richter (1944), Richter (1958), and Allen et al. (1965) regarding seismicity have stood the test of time. More numerous and improved locations of smaller earthquakes, over a greater span of time, have refined statistics and allowed the accurate mapping of sometimes blind faults, the determination of 3D crustal structure, and the determination of site amplification in the major sedimentary basins. The introduction of the broadband seismic stations has supported research in source modeling and earthquake physics that was not possible with previous technology. The large number of events in the catalog has enabled the use of statistical methods that estimate risk and test prediction hypotheses (Field et al., 2008).

\section{Conclusions}

The SCSN has been in operation for more than $77 \mathrm{yrs}$, since 1932, and has recorded and located over 470,000 earthquakes. Station density and technological sophistication have both increased steadily since 1932 leading to increased catalog completeness and precision over time. The first instrumental earthquake magnitude scale, $M_{\mathrm{L}}$, and the Wood-Anderson seismometer that it is based on, were both inextricably entwined with the SCSN data. $M_{\mathrm{L}}$ is still used, having been adapted to use synthetic Wood-Anderson amplitudes computed from other short-period and broadband instruments, for most of the earthquakes, although several other magnitude scales, including moment magnitudes, $M_{\mathrm{w}}$, are also represented. The catalog includes three $M>7$ mainshock-aftershock sequences, as well as data from another three ( $M$ 6.4, $M$ 6.7, and $M$ 6.7) mainshocks that caused major damage in the Los Angeles area.
The completeness level of the catalog varies with time and geographic location. On average, the catalog is complete for $M_{\mathrm{c}} \geq 3.2$ since 1932 and $M_{\mathrm{c}} \geq 1.8$ since 1981, with exceptions in the early hours or days of large aftershock sequences and regions along the edges of the network. Many regions, such as the Anza area and the Coso geothermal area, within the core of the coverage area, are now complete to $M_{\mathrm{c}}<1.0$. The overall seismicity rate has remained fairly constant for the last $77 \mathrm{yrs}$, except for major aftershock sequences. Allowing for catalog incompleteness in major sequences and known magnitude problems, the southern California $b$-value estimates are consistent with $b=1.0$. However, a $b$-value of $\sim 1.0$ underpredicts the rate of $M>6$ earthquakes, thus suggesting different statistics for the large earthquakes. We find that $b$-value and $M_{\mathrm{c}}$ changes as a function of time are probably more diagnostic of catalog problems than they are of real changes in the seismicity rate. The overall spatial and temporal seismicity patterns do not correspond well to high slip-rate late Quaternary faults, suggesting that the cause of small and major earthquakes may be different. Small earthquakes have historically been much more widely distributed geographically than the major earthquakes $(M>7.5)$, which have been confined to late Quaternary mapped faults.

The SCSN data and the catalog have served as major resources for seismology research and civic and emergency planning and response, public outreach, and public consciousness on the subject of earthquake preparedness.

\section{Data and Resources}

The Caltech/USGS Southern California Seismic Network (SCSN) earthquake catalog, along with metadata and other ancillary data, such as moment tensors and focal mechanisms if available, is obtained from the Southern California Earthquake Data Center (SCEDC). The Web site for the SCEDC is http://www.data.scec.org/index.html (last accessed January 2010). These data are based on seismograms recorded by the SCSN at the Seismological Laboratory at the California Institute of Technology and the U.S. Geological Survey Pasadena Office. The ANSS catalog can be searched at http://www.ncedc.org/anss/catalog-search.html (last accessed January 2010). The software used is described in the text of the article. Maps and plots were generated using the Generic Mapping Tool (GMT; Wessel and Smith, 1998; http://gmt.soest.hawaii.edu/; last accessed January 2010).

\section{Acknowledgments}

A huge cast of individuals has worked on the data processing for the Southern California earthquake catalog over time. It is not possible to name them all, but the following come to mind: C. R. Allen, V. Appel, A. C. Blanchard, A. S. Bryant, A. Burciaga, S. B. Choi, J. Cooper, J. Cronk, A. Dejohn, R. Ewald, J. Franck, S. A. Fischer, D. Ford, M. Fouch, W. Franzen, M. E. Friedman, G. S. Fuis, K. Kahler, R. R. Geary, L. Gee, P. T. German, D. D. Given, S. Green, A. J. Guarino, G. Gutierrez, J. Haas, K. Hafner, W. Heaton, J. A. Hileman, W. Huston, D. J. Jenkins, C. E. Johnson, M. Johnson, L. M. Jones, G. Killeen, V. D. Lamanuzzi, C. Loeffler, J. Mori, 
J. M. Nordquist, R. Norris, S. Perry, R. Peters, J. Polet, H. Qian, B. A. Reed, C. F. Richter, K. J. Richter, E. Riggs, R. Robb, P. Roberts, H. Rico, N. J. Scheckel, V. Taylor, M. Turner, L. A. Wald, K. M. Watts, D. Wells, J. H. Whitcomb, and B. Wu. An additional host of people, including but not limited to J. Batten, R. Bhadha, L. Blaney, G. Cone, R. Cone, W. Curtis, A. Devora, R. S. Dollar, D. J. Johnson, C. Koesterer, F. Lehner, J. Lower, S. Lydeen, P. Maechling, W. Miller, J. Romo, T. Saleh, S. Schwarz, P. Small, R. A. Taylor, and A. W. Walter, have installed and maintained the stations, the computer hardware, and written the software. B. Wu and E. Yu helped with figures, and M. Boese, G. Cua, K. Felzer, L. Jones, H. Kanamori, A. Michael, and one anonymous reviewer provided comments that improved the manuscript. The Southern California Earthquake Data Center (SCEDC) (lead by R. Clayton and E. Yu) archives and distributes the SCSN data. The SCSN has been supported by NEHRP/USGS and ANSS through a series of Cooperative Agreement (the most recent is \# 07HQAG0007), the California Emergency Management Agency (CalEMA) through a series of contracts (the most recent is \# 6028-2), and the IRIS/USArray and IRIS/GSN through Contract Numbers 473 and 310; the SCEDC is supported by SCEC that is funded by NSF Cooperative Agreement EAR-0529922 and USGS Cooperative Agreement 07HQAG0008. Caltech, Division of Geological and Planetary Sciences, Seismological Laboratory contribution number 10024. SCEC contribution number 1277.

\section{References}

Aki, K. (1965). Maximum likelihood estimate of $b$ in the formula $\log N=$ $a-b M$ and its confidence limits, Bull. Earthq. Res. Inst. 43, 237-239.

Allen, R. (1982). Automatic phase pickers: Their present use and future prospects, Bull. Seismol. Soc. Am. 72, 225-242.

Allen, C. R., P. St. Amand, C. F. Richter, and J. M. Nordquist (1965). Relationship between seismicity and geologic structure in the southern California region, Bull. Seismol. Soc. Am. 55, 753-797.

Benioff, H. (1932). A new vertical seismograph, Bull. Seismol. Soc. Am. 22, 155-169.

Brune, J. N. (1970). Tectonic stress and the spectra of seismic shear waves from earthquakes, J. Geophys. Res. 75, 4997-5009.

Bryant, S. A., and L. M. Jones (1992). Anomalously deep crustal earthquakes in the Ventura Basin, southern California, J. Geophys. Res. 97, 437-447.

Clinton, J. E., E. Hauksson, and K. Solanki (2006). An evaluation of the SCSN moment tensor solutions: Robustness of the $M_{\mathrm{w}}$ magnitude scale, style of faulting, and automation of the method, Bull. Seismol. Soc. Am. 96, 1689-1705.

Conover, W. J. (1999). Practical nonparametric statistics, In Applied Probability and Statistics Section, Third Ed., John Wiley and Sons, Inc., New York.

Dreger, D. S., and D. V. Helmberger (1990). Boadband modeling of local earthquakes, Bull. Seismol. Soc. Am. 90, 1162-1179.

Felzer, K. R., and T. Cao (2008). Appendix H: WGCEP historical California earthquake catalog, U.S. Geol. Surv., Open-File Rept. 2007-1437H, $127 \mathrm{pp}$.

Field, E. H., T. E. Dawson, K. R. Felzer, A. D. Frankel, V. Gupta, T. H. Jordan, T. Parsons, M. D. Petersen, R. S. Stein, R. J. Weldon II, and C. J. Wills (2008). The uniform California earthquake rupture forecast, Version 2 (UCERF 2) USGS, Open-File Rept. 2007-1437, CGS Special Report 203.

Friedman, M. E., J. H. Whitcomb, C. R. Allen, and J. A. Hileman (1976). Seismicity of the Southern California region; 1 January 1982 to 31 December 1974, Seismological Laboratory, Division of Geological and Planetary Sciences, California Institute of Technology, Pasadena, California.

Gutenberg, R., and C. F. Richter (1944). Frequency of earthquakes in California, Bull. Seismol. Soc. Am. 34, 185-188.

Gutenberg, B., and C. F. Richter (1956). Earthquake magnitude, intensity, energy and acceleration, Bull. Seismol. Soc. Am. 46, 105-145.

Hadley, D., and H. Kanamori (1977). Seismic structure of the Transverse ranges, California, Geol. Soc. Am. Bull. 88, 1469-1478.
Hanks, T., and H. Kanamori (1979). A moment magnitude scale, J. Geophys. Res. 84, 2348-2350.

Hauksson, E. (2000). Crustal structure and seismicity distribution adjacent to the Pacific and North American plate boundary in southern California, J. Geophys. Res. 105, 13,875-13,903.

Hauksson, E. (2010). Spatial separation of large earthquakes, aftershocks, and background seismicity: Analysis of interseismic and coseismic seismicity patterns in Southern California, Pure Appl. Geophys 167, (in press).

Hauksson, E., and S. J. Gross (1991). Source parameters of the 1933 Long Beach earthquake, Bull. Seismol. Soc. Am. 81, 81-98.

Hauksson, E., and P. Shearer (2005). Southern California hypocenter relocation with waveform cross-correlation, part I: Results using the double-difference method, Bull. Seismol. Soc. Am. 95, 896-903.

Hauksson, E., L. M. Jones, and K. Hutton (2002). The $1999 M_{\mathrm{w}} 7.1$ Hector Mine, California, earthquake sequence: Complex conjugate strike-slip faulting, Bull. Seismol. Soc. Am. 92, 1154-1170.

Hauksson, E., L. M. Jones, K. Hutton, and D. Eberhart-Phillips (1993). The 1992 Landers earthquake sequence: Seismological observations, J. Geophyis. Res. 98, 19,835-19,858.

Hauksson, E., P. Small, K. Hafner, R. Busby, R. Clayton, J. Goltz, T. Heaton, K. Hutton, H. Kanamori, J. Polet, D. Given, L. M. Jones, and R. Wald (2001). Southern California seismic network: Caltech/USGS element of TriNet 1997-2001, Seism. Res. Lett. 7, 697-711.

Hellweg, M., R. Uhrhammer, K. Hutton, A. Walter, P. Lombard, and E. Hauksson (2007). Recalibrating $M_{\mathrm{L}}$ for the California Integrated Seismic Network (Abstract S43A-1057), Eos Trans. AGU 88, no. 52 (Fall Meet. Suppl.), S43A-1057.

Hileman, J. A., C. R. Allen, and J. M. Nordquist (1973). Seismicity of the Southern California region, 1 January 1932 to 31 December 1972, Seismological Laboratory, California Institute of Technology, Pasadena, California.

Hill, D. P., J. P. Eaton, and L. M. Jones (1990). Seismicity, 1980-86, in The San Andreas Fault System, California, U.S. Geol. Surv. Professi. Pap. $1515,115-151$.

Hutton, L. K., and D. M. Boore (1987). The $M_{\mathrm{L}}$ scale in southern California, Bull. Seismol. Soc. Am. 77, 2074-2094.

Hutton, L. K., and L. M. Jones (1993). Local magnitudes and apparent variations in seismicity rates in southern California, Bull. Seismol. Soc. Am. 83, 313-329.

Hutton, L. K., L. M. Jones, E. Hauksson, and D. D. Given (1991). Seismotectonics of southern California, in Neotectonics of North America, D. B. Slemmons, E. R. Engdahl, M. D. Zoback, and D. D. Blackwell (Editors), Geol. Soc. Am., Decade Map, Vol I, Boulder, Colorado.

Ishimoto, M., and K. Iida (1939). Observations of earthquakes registered with the microseismograph constructed recently, Bull. Earthq. Res. Inst. 17, 443-478.

Jennings, C. W. (1995). New fault map of California and adjacent areas, Calif. Geol. 48, 31-42.

Johnson, C. E. (1979). I. CEDAR-An approach to the computer automation of short-period local seismic networks, Ph.D. Thesis, California Institute of Technology.

Johnson, C. E., A. Bittenbinder, B. Boegart, L. Dietz, and W. Kohler (1995). Earthworm: A flexible approach to seismic network processing, IRIS Newslett. XIV, no. 2, 1-4.

Kagan, Y., D. D. Jackson, and Y. Rong (2006). A new catalog of southern California earthquakes, 1800-2005, Seism. Res. Lett. 77, 30-38.

Kanamori, H. (1977). The energy release in great earthquakes, J. Geophys. Res. 82, 2981-2987.

Kanamori, H. (1978). Quantification of earthquakes, Nature 271, no. 5644, 411-414.

Kanamori, H., and D. M. Hadley (1975). Crustal structure and temporal velocity change in southern California, Pure Appl. Geophys. 113, 257-280.

Kanamori, H., E. Hauksson, and T. Heaton (1991). TERRAscope and the CUBE project at Caltech, Eos Trans. AGU 72, 564. 
Kanamori, H., J. Mori, E. Hauksson, T. H. Heaton, L. K. Hutton, and L. M. Jones (1993). Determination of earthquake energy release and $M_{\mathrm{L}}$ using Terrascope, Bull. Seismol. Soc. Am. 83, 330-346.

Kilb, D., V. G. Martynov, and F. L. Vernon (2007). Aftershock detection thresholds as a function of time: Results from the ANZA seismic network following the 31 October $2001 M_{\mathrm{L}} 5.1$ Anza, California, earthquake, Bull. Seismol. Soc. Am. 97, 780-792.

Klein, F. W. (2002). User's Guide to HYPOINVERSE-2000, a Fortran program to solve for earthquake locations and magnitudes, U.S. Geol. Surv. Open-File Rept. 02-171, 123 pp.

Lay, T., and T. C. Wallace (1995). Modern Global Seismology, Academic Press, New York, 517 pp.

Lee, W. H. K., R. E. Bennett, and K. L. Meagher (1972). A method of estimating magnitude of local earthquakes from signal duration, U.S. Geol. Surv. Open-File Rept. 72-223, 28 pp.

Lehner, F. E. (1962). Brief description of the Ranger lunar seismograph, Proc. of the IRE 50, 2297.

Lin, G., P. M. Shearer, and E. Hauksson (2007). Applying a threedimensional velocity model, waveform cross-correlation, and cluster analysis to locate southern California seismicity from 1981 to 20005, J. Geophys. Res. 112, B12309.

Nicholson, C., L. Seeber, P. Williams, and L. R. Sykes (1986). Seismicity and fault mechanics through the eastern Transverse Ranges, California: Block rotation, strike-slip faulting and low-angle thrusts, J. Geophys. Res. 91, 4891-4908.

Nordquist, J. M. (1962). A special-purpose program for earthquake location with an electronic computer, Bull. Seismol. Soc. Am. 52, 431-437.

Ogata, Y., and K. Katsura (1993). Analysis of temporal and spatial heterogeneity of magnitude frequency distribution inferred from earthquake catalogs, Geophys. J. Int. 113, 727-738.

Page, M., K. Felzer, R. Weldon, and G. Biasi (2009). The magnitudefrequency distribution on the southern San Andreas fault follows the Gutenberg-Richter distribution (Abstract S31C-06), Eos Trans. $A G U$ 89, 53 (Fall Meeting Suppl.), S31C-06.

Reasenberg, P. A. (1985). Second-order moment of central California seismicity, 1969-1982, J. Geophys. Res. 90, 5479-5495.

Reasenberg, P. A., and L. M. Jones (1989). Earthquake hazard after a mainshock in California, Science 265, 1173-1176.

Richter, C. F. (1935). An instrumental magnitude scale, Bull. Seismol. Soc. Am. 25, 1-31.

Richter, C. F. (1958). Elementary Seismology, W. H. Freeman, San Francisco.

Schorlemmer, D., and J. Woessner (2008). Probability of detecting an earthquake, Bull. Seismol. Soc. Am. 98, 2103-2117.

Taylor, R. J. (1997). An Introduction to Error Analysis, University of Science Books, Sausalito, California, 327 pp.

Thatcher, W., and T. Hanks (1973). Source parameters of southern California earthquakes, J. Geophys. Res. 78, 8547-8576.

Thurber,C.H. (1993). Local earthquake tomography: Velocities and $V_{P} / V_{S}-$ theory, in Seismic Tomography: Theory and Practice, H. M. Iyer and K. Kirahara (Editors), Chapman and Hall, London, 563-583.
Toppazada, T. R., C. R. Real, and D. L. Parke (1981). Preparation of isoseismal maps and summaries of reported effects for pre-1900 California earthquakes, Calif. Div. Mines Geol. Spec. Rept. 81-11 SAC, $182 \mathrm{pp}$.

Uhrhammer, R. A., and E. R. Collins (1990). Synthesis of Wood-Anderson seismograms from broadband digital records, Bull. Seismol. Soc. Am. 80, 702-716.

Utsu, T. (1965). A method for determining the value of $b$ in a formula $\log n=a-b M$ showing the magnitude frequency for earthquakes, Geophys. Bull. Hokkaido Univ. 13, 99-103.

Wald, L. A., D. D. Given, J. Mori, L. M. Jones, and L. K. Hutton (1990). The southern California network bulletin, January-December 1988, U.S. Geol. Surv. Open-File Rept. 90-499.

Wang, Q., D. D. Jackson, and Y. Y. Kagan (2009). California earthquakes, 1800-2007: A unified catalog with moment magnitudes, uncertainties, and focal mechanisms, Seism. Res. Lett. 80, no. 3, 446-457, doi 10.1785/gssrl.80.3.446.

Weldon, R. J., and E. Humphreys (1986). A kinematic model of southern California, Tectonics 5, 33-48.

Wessel, P., and W. H. F. Smith (1998). New version of the Generic Mapping Tools released, Eos Trans. AGU 79, 579.

Wiemer, S. (2001). A software package to analyze seismicity: ZMAP, Seism. Res. Lett. 373-382.

Woessner, J., and S Wiemer (2005). Assessing the quality of earthquake catalogues: Estimating the magnitude of completeness and its uncertainties, Bull. Seismol. Soc. Am. 95, 684-698.

Wood, H. O. (1916). The earthquake problem in the western United States, Bull. Seismol. Soc. Am. 6, 196-217.

Wood, H. O. (1947a). Earthquakes in southern California with geologic relations: (Part one), Bull. Seismol. Soc. Am. 37, 107-157.

Wood, H. O. (1947b). Earthquakes in southern California with geologic relations: Part two, Bull. Seismol. Soc. Am. 37, 217-258

Wood, H. O., and J. A. Anderson (1925). Description and theory of the torsion seismometer, Bull. Seismol. Soc. Am. 15, 1-72.

Seismological Laboratory

California Institute of Technology

Pasadena, California 91125

kate@gps.caltech.edu

Hauksson@gps.caltech.edu

(K.H., E.H.)

ETH

Swiss Seismological Service

ETH Zurich, Sonneggstrasse 5

CH-8092 Zurich

j.woessner@sed.ethz.ch

(J.W.)

Manuscript received 2 June 2009 